\title{
High Strength Al-Alloys: Microstructure, Corrosion and Principles of Protection
}

\author{
Anthony E. Hughes ${ }^{1}$, Nick Birbilis², Johannes M.C. Mol ${ }^{3 a}$, \\ Santiago J. Garcia ${ }^{3 b}$, Xiaorong Zhou ${ }^{4}$ and George E. Thompson ${ }^{4}$ \\ ${ }^{1}$ CSIRO Materials Science and Technology, Melbourne \\ ${ }^{2}$ Department of Materials Engineering, Monash University, Cloyton \\ ${ }^{3} T U$ Delft, Department of Materials Science and Engineering a and \\ Novel Aerospace Materials, Aerospace Engineering $b$, Delft \\ ${ }^{4}$ School of Materials, The University of Manchester, Manchester \\ 1,2Australia \\ ${ }^{3}$ Netherlands \\ ${ }^{4}$ United Kingdom
}

\section{Introduction}

Aluminium alloys have highly heterogeneous microstructures compared to many other metal alloys. This heterogeneity originates from alloy additions and impurities which combine to produce both the desired microstructure as well as undesired, large particles, called constituent particles (and residual impurity particles) which have a range of compositions. In corrosion science these latter particles are commonly referred to as intermetallic (IM) particles. The heterogeneous nature of aluminium alloys is most evident in members of the high strength alloys of the 2xxx, 6xxx, 7xxx and $8 \times x x$ and most particularly the $2 x x x$ series alloys where alloy additions are required to obtain the high strength to weight ratio properties of these materials.

For many years now, the study of corrosion in these alloys was, and in many instances continues to be, a phenomenological exercise. So the literature on this subject largely involves studies of a small number of intermetallic (IM) particles under a variety of conditions which are difficult to relate to each other in order to form a more general model of corrosion in highly heterogeneous aluminium alloys. This is particularly true for the 2xxx series of alloys which lacks a system to unambiguously categorise these IM particles compositional variation makes it difficult to relate these particles with well know composition, crystallography and electrochemistry. The difficulty in devising such a system should not be underestimated since the intermetallic particles form at various stages during manufacture, individual particles have compositionally different phase domains and their distribution including the spatial relationship to one another is often dictated by the processing route. Nevertheless, in recent years there have been significant advances in the understanding of both the microstructure of some high strength alloys as well as its influence on corrosion. These advances have their foundations in the wider accessibility to a range of newer electrochemical and physicochemical characterisation techniques. The use of advanced electrochemical techniques has led to a greater understanding of the properties of the intermetallic particles themselves and 
their roles in corrosion of alloys. The physico-chemical studies have led to a better characterisation of the composition of intermetallic particles, and, importantly of their spatial distributions. The convergence of the electrochemical and physicochemical approaches, in combination with modelling, is leading to a statistical basis for understanding the influence of the intermetallic particles on corrosion of aluminium alloys. This chapter therefore aims to summarise our current understanding of the microstructure of high strength aluminium alloys, particularly the more microstructurally complex alloys such as the $2 x x x$, and $7 x x x$ series alloys. It then looks at how different components of the microstructure contribute to corrosion processes and finishes by examining the principles of protection of aluminium alloys using traditional and newer techniques used to assess the degree of protection.

\section{Microstructure}

\subsection{Aluminium alloys in general}

While aluminium alloy microstructure, for some specific alloys, is relatively well known, the microstructures for some high strength aluminium alloys, particularly the older AA2 $x x x$ alloys, is not well described or understood in the scientific literature, particularly the corrosion literature. This is partially due to manufacturing processing conditions which do not realise the intended microstructure and partially due to quasi or non-equilibrium microstructure existing in real alloys because of the difficulty of obtaining full thermodynamic equilibrium. Typical examples of common high strength alloys used in aircraft manufacture, for example, include AA2024-T3, AA7075-T6 and AA6061-T6. This section, therefore, provides a general overview of the relationship between processing and microstructure.

Processing can significantly alter the bulk microstructure, resulting in microstructural gradients and zones with different characteristics. A good example of these changes can be found in wrought alloy sheet product. First there is a gradient in grain size and constituent particle size across the sheet. Second, shear deformation, resulting from rolling, creates a surface layer called a near surface deformed layer (NSDL) with a very fine microstructure which may have a different degree of precipitation compared to the bulk depending on the heat treatments.

\subsection{Aluminium production}

Bauxite production has increased $50 \%$ in the past decade to an all time high of over 200 million tonnes worldwide; with Australia the largest producer, followed by China and Brazil. Four tonnes of bauxite are used to produce two tonnes of alumina, which can then produce one tonne of aluminium. Recycling of aluminium requires $95 \%$ less energy than for primary aluminium production. In order to meet the mechanical and corrosion performance requirements for many alloys as required under performance specifications, much of the recycled metal must be blended or diluted with primary metal to reduce impurity levels. The result is that, in many cases, recycled metal tends to be used primarily for lower grade casting alloys and products (Polmear 2004), however with $\sim 35 \%$ of $\mathrm{Al}$ being produced from recycled material, the future ramifications for corrosion will need addressing.

\subsection{Physical metallurgy of aluminium alloys}

The functional properties of aluminium alloys (mechanical, physical, and chemical) depend on alloy composition and alloy microstructure as determined by casting conditions and 
thermomechanical processing. Only a small number of metals have sufficient solubility to serve as major alloying elements (Das 2006) and alloys derived from these few form the basis of the present classes of commodity Al-alloys. Magnesium, zinc, copper and silicon have significant solubility, whilst additional elements (of $<1 \%$ solubility) are also used to confer improvements to alloy properties, namely grain refinement, and such elements include manganese, chromium, zirconium, titanium and less commonly (due to cost) scandium (Hatch 1984; Polmear 2004). Alloying of Manganese with Fe-containing intermetallic particles reduces the electrochemical activity of these Fe-containing particles thus improving the corrosion resistance of the alloy (Polmear 1995)

The low strength of pure aluminium ( 10 MPa) mandates alloying. The simplest strengthening technique is solution hardening, whereby alloying additions have appreciable solid solubility over a wide range of temperatures and remain in solution after many thermal cycles.

The most significant increase in strength for aluminium alloys is derived from age hardening (often called precipiation hardening) which can result in strengths as high as 800 $\mathrm{MPa}$. The principal of age hardening requires that the solid solubility of alloying elements decreases with temperature. The age hardening process can be summarised by the following stages:

i. solution treatment at a temperature within a single phase region to dissolve the alloying element(s)

ii. quenching of the alloy to obtain what is termed a supersaturated solid solution

iii. decomposition of the supersaturated solid solution at ambient or moderately elevated temperature to form finely dispersed precipitates.

The fundamental aspects of decomposition of a supersaturated solid solution are complex (Raviprasad, Hutchinson et al. 2003; Kovarik, Miller et al. 2006; Winkelman, Raviprasad et al. 2007). Typically however, Guinier-Preston (GP) zones and intermediate phases are formed as precursors to the equilibrium precipitate phase (Hatch 1984) (Figure 1 reveals a

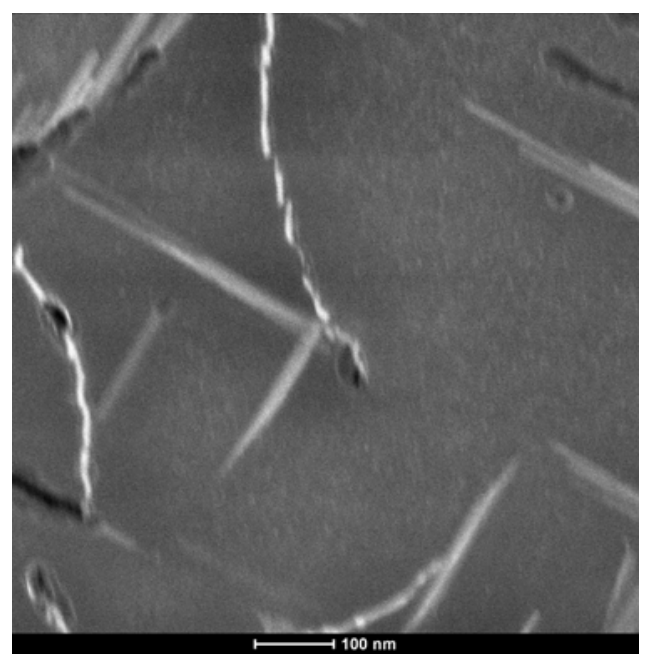

Fig. 1. Dark field scanning transmission electron micrograph of coarse $\mathrm{Al}_{2} \mathrm{CuMg}$ precipitate particles in an AA2xxx (Al-Cu-Mg) alloy - imaged down $<100>$ zone axis 
typical micrograph showing precipitate particles). GP zones are formed when solute atoms (e.g. $\mathrm{Cu}, \mathrm{Zn}$ and $\mathrm{Mg}$ ) accumulate along preferred crystal directions in the $\mathrm{Al}$ lattice and form a strengthening phase.

Properties can be enhanced further by careful thermo-mechanical processing that may include heat treatments like duplex aging and retrogression and re-aging. Maximum hardening in commercial alloys is often achieved when the alloy is cold worked by stretching after quenching and before aging, increasing dislocation density and providing more heterogeneous nucleation sites for precipitation. Whilst only moderate increases in strength can be obtained in Al-alloys by exploiting the Hall-Petch ${ }^{1}$ relationship (Polmear 1995), refinement is important for a range of properties including fracture and toughness. Grain refinement in aluminium alloys is achieved by additions of small amounts of low solubility elements such as Ti and B to provide grain nuclei, and by recrystallisation control using precipitates called dispersoids (typically $40 \times 200 \mathrm{~nm}$ ) which are formed from aluminium and alloying additions such as $\mathrm{Cu}, \mathrm{Cr}, \mathrm{Zr}$ or $\mathrm{Mn}$ to promote insoluble particles which subsequently can restrict or pin grain growth.

The microstructures developed in aluminium alloys are complex and incorporate a combination of equilibrium and non-equilibrium phases. Non-equilibrium phases exist in essentially all high-strength alloys, and as such, their properties are very temperature dependent.

Typical commercial alloys can have a chemical composition incorporating as many as ten alloying additions (with a number of these additions being unavoidable impurities). As such, from a corrosion perspective, one must understand the role of impurity elements on microstructure. Whilst not of major significance to alloy designers, impurity elements such as $\mathrm{Fe}, \mathrm{Mn}$ and $\mathrm{Si}$ can form insoluble compounds called constituent particles. These are comparatively large and irregularly shaped with characteristic dimensions ranging from 1 to $\sim 50 \mu \mathrm{m}$. These particles are formed during alloy solidification and are not appreciably dissolved during subsequent thermo-mechanical processing. Rolling and extrusion tend to break-up and align constituent particles within the alloy. Often constituents are found in clusters made up of several different intermetallic compound types. Because these particles are rich in alloying elements, their electrochemical behaviour can be significantly different to the surrounding matrix phase. In most alloys pitting is associated with specific constituent particles present in the alloy (Buchheit 1995; Liao, Olive et al. 1998; Wei, Liao et al. 1998; Guillaumin and Mankowski 1999; Park, Paik et al. 1999; Ilevbare, Schneider et al. 2004; Schneider, Ilevbare et al. 2004; Lacroix, Ressier et al. 2008; Lacroix, Ressier et al. 2008; Boag, Taylor et al. 2010. These are discussed below.

\subsection{Alloy classification}

The International Alloy Designation System (IADS) gives each wrought alloy a four-digit number of which the first digit is assigned on the basis of the major alloying element(s) (Polmear 1995; Winkelman, Raviprasad et al. 2007)). The main alloying element for AA2xxx is $\mathrm{Cu}$ and for AA7xxx is $\mathrm{Zn}$, with Mg playing a important role is both classes of alloys.

For cast aluminium alloys, alloy designations principally adopt the notation of the Aluminium Association System. The casting compositions are described by a four-digit system that incorporates three digits followed by a decimal (described in more detail in

${ }^{1}$ The Hall-Petch relationship states that the yield strength is proportional to the inverse square root of the grain size. 
(Hatch 1984)). The temper designation system adopted by the Aluminium Association is similar for both wrought and cast aluminium alloys.

\section{$2 \mathbf{x x x}$}

Copper is one of the most common alloying additions, since it has appreciable solubility and a significant strengthening effect by its promotion of an age hardening response. These alloys were the foundation of the modern aerospace construction industry and, for example AA2024 (Al-4.4Cu-1.5Mg-0.8Mn), can achieve strengths of up to $520 \mathrm{MPa}$ depending on temper. The microstructure of this series is considered further below. $\mathrm{Cu}$, however, is one of the nobler alloying elements and therefore supports a high rate of oxygen reduction which drives one half of the galvanic reaction. The cell is completed by the dissolution of any element less noble, particularly $\mathrm{Al}$ thereby facilitating the onset and propagation of corrosion.

\section{$7 \mathbf{x x x}$}

The Al-Zn-Mg alloy system provides a range of commercial compositions, primarily where strength is the key requirement. Al-Zn-Mg-Cu alloys have traditionally offered the greatest potential for age hardening and as early as 1917 a tensile strength of $580 \mathrm{MPa}$ was achieved, however, such alloys were not suitable for commercial use until their high susceptibility to stress corrosion cracking could be moderated. Military and commercial aerospace needs led to the introduction of a range of high strength aerospace alloys of which AA7075 (Al-5.6Zn$2.5 \mathrm{Mg}-1.6 \mathrm{Cu}-0.4 \mathrm{Si}-0.5 \mathrm{Fe}-0.3 \mathrm{Mn}-0.2 \mathrm{Cr}-0.2 \mathrm{Ti}$ ) is perhaps the most well known, and which is now essentially wholly superseded by AA7150 (or the 7x50 family). The high strength 7xxx series alloys derive their strength from the precipitation of $\eta$-phase $\left(\mathrm{MgZn}_{2}\right)$ and its precursor forms. The heat treatment of the $7 x \times x$ series alloys is complex, involving a range of heat treatments that have been developed to balance strength and stress corrosion cracking performance, comprising secondary (or more) heat treatments that can include retrogression and re-aging (Sprowls 1978).

\subsection{Processing of aluminium alloys}

The surface layers of aluminium alloys can be altered during processing and storage environments, which adds complexity to the surface finishing and corrosion performance (Fishkis and Lin 1997). These effects include the formation of near surface deformed layers (NSDL) during mechanical processing, the elongation of crystalline structure during rolling and extrusion, breakup of brittle intermetallic particles, differences in surface roughness and porosity, and the segregation of specific alloying elements to the surface.

Casting from the melt is the first processing step. The three most commonly used processes are sand casting, permanent mould casting and die casting. Sand moulds are gravity fed whereas the metal moulds used in permanent mould casting are either gravity fed or by using air or gas pressure to force metal into the mould. In high pressure die castings, parts up to approximately $5 \mathrm{~kg}$ are made by injecting molten aluminium alloy into a metal mould under substantial pressure using a hydraulic ram.

For large production scale, direct chill (DC) casting is a semi-continuous process used for the production of rectangular ingots or slab for rolling to plate, sheet, foil and cylindrical ingots or billet for extruded rods, bars, shapes, hollow sections, tube and wire. DC casting is the first step in the production of $\mathrm{Al}$ alloys prior to the thermomechanical treatments, and whilst it may appear to be a topic not requiring discussion in such a chapter, it is important 
to realise that corrosion performance of an alloy is dictated by each processing step, starting with the solidification of the molten alloy during DC casting.

DC casting starts by pouring molten metal into a water-cooled aluminium or copper mould. Accumulation of alloying elements at the surface can occur through segregation processes where mobile elements diffuse from the bulk and from grain boundaries. In general, the surface enriched elements have a high negative free energy for oxide formation and high diffusion coefficient through aluminium metal. Such elements include lithium, magnesium and silicon (Carney, Tsakiropoulos et al. 1990). The segregation occurs during forming and heat treatments and has been demonstrated to influence the corrosion and wear properties of the alloys (Nisancioglu 2004).

Thermodynamic considerations often fail to correctly predict the phase and solid solution content of an as-cast microstructure because of the non-equilibrium nature of solidification during DC casting. This is important as alloy corrosion properties are controlled by solid solution levels and intermetallic phase crystallography and morphology, which depend on complex kinetic competitions during nucleation and growth. Most importantly, the constituent particles do not appreciably dissolve during subsequent solution heat treatment, and will thus persist into the final product.

\subsection{Surface microstructures}

Fabrication processes, including rolling, machining and mechanical grinding, produce aluminium products of the required gauge thickness and shape for various applications. Rolling blocks or slabs that are up to many tonnes, requires heating to temperatures up to $500^{\circ} \mathrm{C}$ and passing through a breakdown mill using heavy reductions per pass to reduce the slab gauge from as large as $5000 \mathrm{~mm}$ down to 15 to $35 \mathrm{~mm}$. The slab surface undergoes intense shear deformation during this process and a NSDL develops. The shearing process also influences IM particles below the surface resulting in a larger number of IM particles in the vicinity of the surface than in the body of the material. This is not as a result of precipitation processes but is due to fragmentation of brittle particles during rolling. Hence the particle number density at the surface is higher, but the percentage of surface area is the same indicating particle fracture rather than new particle formation (Hughes, Boag et al. 2006). The characteristics of the surface of sheet AA2024-T3 with respect to the body of the material (obtained by polishing) are compared in Table 1 (Hughes, Boag et al. 2006). The slab from the breakdown mill is then typically hot rolled on a multistand tandem mill down to a gauge of 2.5 to $8 \mathrm{~mm}$. Hot rolling deforms the original cast structure with the grains being elongated in the rolling direction. The elongated microstructure developed during hot

\begin{tabular}{|l|l|l|}
\hline IM Particle Characteristic & Body & Surface \\
\hline Number Density: & $5.3 \times 10^{5} \mathrm{~cm}^{-2}$ & $11.7 \times 10^{5} \mathrm{~cm}^{-2}$ \\
\hline Average Particle Size: & $6.66 \mu \mathrm{m}^{2}$ & $1.98 \mu \mathrm{m}^{2}$ \\
\hline Median Particle Size: & $1.6 \mu \mathrm{m}^{2}$ & $1.2 \mu \mathrm{m}^{2}$ \\
\hline \%Surface Area: & $2.89 \%$ & $2.82 \%$ \\
\hline Total Particles per 1mm²: & 5300 & 11690 \\
\hline Minimum Particle Size: & $0.40 \mu \mathrm{m}^{2}$ & $0.34 \mu \mathrm{m}^{2}$ \\
\hline Maximum Particle Size: & $327 \mu \mathrm{m}^{2}$ & $114 \mu \mathrm{m}^{2}$ \\
\hline
\end{tabular}

Table 1. IM particle size (area) for polished (body) and as-rolled (surface) AA 2024 
rolling can have a profound effect on corrosion properties like stress corrosion cracking and exfoliation corrosion. For example, the exfoliation corrosion of 7xxx alloys was shown to be due to manganese segregation to interfaces (grain boundaries and the external surface) during DC casting (Evans 1971).

Typically, a NSDL is characterised by ultra-fine, equiaxed grains, with grain boundaries decorated by nano-sized oxide particles (Fishkis and Lin 1997; Leth-Olsen, Nordlien et al. 1998; Plassart 2000; Scamans 2000; Afseth, Nordlien et al. 2001; Zhou, Thompson et al. 2003; Liu, Frolish et al. 2010; Scamans, Frolish et al. 2010; Thompson 2010; Zhou 2011). It is associated with the susceptibility of several aluminium alloys to filiform corrosion (Zhou, Thompson et al. 2003; Liu, Zhou et al. 2007; Liu, Laurino et al. 2010). The depth of the modified surface region ranges from a few nanometers (after polishing) to $8 \mu \mathrm{m}$ (during rolling). In the latter case the thickness varies with each rolling pass (Fishkis and Lin 1997). Further, a transition region, characterized by microbands that consist of elongated grains aligned parallel to the working surface, may be sandwiched between the surface regions and the bulk alloy. The deformed layers are stable at ambient temperature, associated with the local presence of a large fraction of high angle grain boundaries. The structure is also stabilized through pinning of the grain boundaries by oxide particles and precipitates (Figure 2). NSDLs with grain boundaries decorated by oxide can survive typical annealing and solution heat treatment processes. As a result, metal finishing and surface treatments are

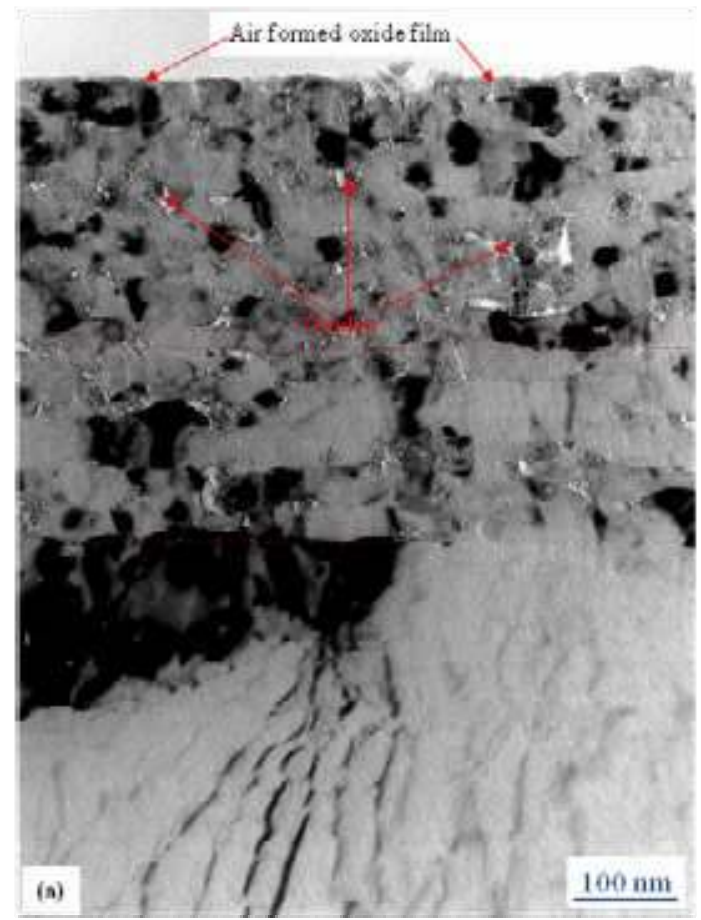

Fig. 2. Transmission electron micrographs of ultramicrotomed sections displaying the surface/near-surface regions of an AA5754 H19 aluminium alloy: (a) as cold rolled, transverse to rolling direction 
required to remove these electrochemically active layers (Leth-Olsen, Nordlien et al. 1997; Mol, Hughes et al. 2004; Hughes, Mol et al. 2005). However, the presence of fine grains alone in the deformed layer, with grain boundaries free of oxide particles, is insufficient to hinder grain coarsening during typical annealing treatments (Zhou 2011).

Importantly, the NSDL has significant influence on properties such as the electrochemical and corrosion behaviour as well mechanical properties, material joining and optical properties. The high population of grain boundaries and severe deformation in the deformed layer promote precipitation of intermetallic particles during subsequent heat treatment (Liu, Zhou et al. 2007). For example, a near-surface deformed layer on AA6111 automotive closure sheet alloy can be generated by mechanical grinding during rectification, as shown in Figure 3 (left). Subsequent paint baking, i.e. thermal exposure at $180^{\circ} \mathrm{C}$ for 30 minutes, promotes the precipitation of $Q$ phase (with various compositions: $\mathrm{Al}_{5} \mathrm{Cu}_{2} \mathrm{Mg}_{8} \mathrm{Si}_{6}$ (Pan, Morral et al. 2010), $\mathrm{Al}_{4} \mathrm{CuMgSi}_{4}$ (Hahn and Rosenfield 1975)) particles, $\sim 20 \mathrm{~nm}$ diameter, at preferred grain boundaries within the deformed layer (Figure 3 centre), but with no precipitates being formed in the underlying bulk alloy. The presence of $Q$ phase precipitation in the near-surface deformed layer increases dramatically the susceptibility of the alloy to cosmetic corrosion that propagates intergranularly, with micro-galvanic coupling between the $\mathrm{Q}$ phase precipitates and the adjacent aluminium matrix providing the driving force (Figure 3(right)).

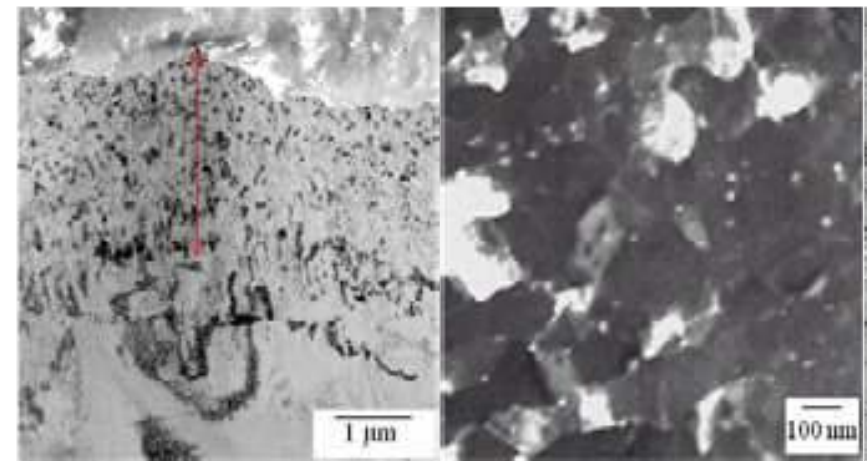

(a)

(b)

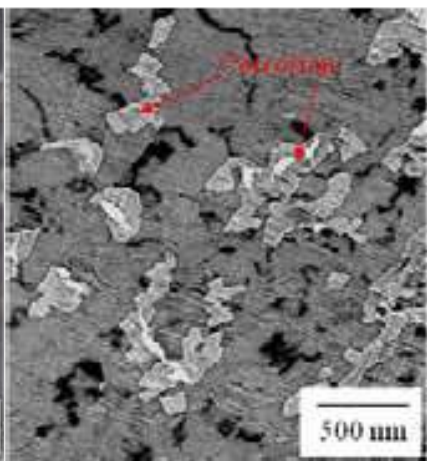

(c)

Fig. 3. Transmission electron micrographs of ultramicrotomed section of AA6111 aluminium alloy after $\mathrm{SHT}$, mechanical grinding and 30 minutes at $180^{\circ} \mathrm{C}$ : (a) bright field image, revealing a near-surface deformed layer and (b) dark field image at increased magnification, revealing grain boundary precipitates. (c) transmission electron micrograph showing intergranular corrosion

\subsection{High strength aluminium alloys AA2xxx and AA7xxx}

Microstructural variation in the high strength Al-alloys exists over a range of scales as reported in Table 2. At the atomic and nanoscopic scale the microstructure is related to the mechanical properties of the alloy. This microstructure involves defect structures, hardening precipitates and dispersoid particles. The high strength of the 2xxx and 7xxx series alloys is due to the hardening precipitates with dispersoids playing a secondary role. Dispersoids can pin grain growth limiting grain size thus making a small contribution to increased 
strength. Defects are generally undesirable since some types of defects give rise to poorer creep resistance. As will be seen below they appear to enhance corrosion in the form of grain etchout and have an influence on intergranular attack.

IM particles such as constituent and impurity particles exist at larger scales with minimum sizes generally between 0.5 to $1.0 \mu \mathrm{m}$. Some types of these particles can achieve local thermodynamic equilibrium during ingot formation. However, processing anomalies may mean that an equilibrium structure is not achieved in practice. Other constituents such as compositions in the Al-Cu-Mg ternary subphase field for 2xxx alloys and Al-Mg-Zn for 7xxx can redissolve during subsequent heat and other treatments.

\begin{tabular}{|l|l|l|}
\hline $\begin{array}{l}\text { Microstructural Feature } \\
\text { and when formed }\end{array}$ & Size & Associated Corrosion \\
\hline $\begin{array}{l}\text { Atomic Defects } \\
\text { (At any time during } \\
\text { processing) }\end{array}$ & $\begin{array}{l}\text { Point Defects <1尺 Line } \\
\text { defect }- \text { tens of nm long } \\
\text { Dislocations }\end{array}$ & $\begin{array}{l}\text { Grain etchout associated } \\
\text { with higher grain stored } \\
\text { energy. }\end{array}$ \\
\hline $\begin{array}{l}\text { Grain Boundaries } \\
\text { (At any time during } \\
\text { processing) }\end{array}$ & $\begin{array}{l}\text { tens of nm wide } \\
\text { (including the zone of } \\
\text { influence such as } \\
\text { depleted zones) }\end{array}$ & $\begin{array}{l}\text { Intergranular attack. Some } \\
\text { evidence from } \\
\text { misorientation angle for } \\
\text { preferred corrosion, } \\
\text { generally only facilitated by } \\
\text { second phase precipitates. }\end{array}$ \\
\hline $\begin{array}{l}\text { Hardening Precipitates } \\
\text { Ageing after Solution } \\
\text { treating) }\end{array}$ & $20 \mathrm{~nm} \times 200 \mathrm{~nm}$ & $\begin{array}{l}\text { Can facilitate intergranular } \\
\text { attack. }\end{array}$ \\
\hline $\begin{array}{l}\text { Dispersoids (Ageing after } \\
\text { Solution treating) }\end{array}$ & $50 \mathrm{~nm} \times 400 \mathrm{~nm}$ & $\begin{array}{l}\text { Under some conditions } \\
\text { undergo preferential attack }\end{array}$ \\
\hline $\begin{array}{l}\text { Constituent Particles and } \\
\text { Impurity Particles } \\
\text { (Primary Ingot Production) }\end{array}$ & Generally $0.5 \mu \mathrm{m}$ to $50 \mu \mathrm{m}$ & $\begin{array}{l}\text { Localised attack of particle if } \\
\text { anodic wrt the matrix and } \\
\text { trenching in surrounding } \\
\text { matrix if cathodic to the } \\
\text { matrix }\end{array}$ \\
\hline $\begin{array}{l}\text { Clusters of particles } \\
\text { (Ingot Working) }\end{array}$ & $50 \mu \mathrm{m}$ to $500 \mu \mathrm{m}$ & $\begin{array}{l}\text { Associated with pitting } \\
\text { attack that propagates into } \\
\text { the surface. }\end{array}$ \\
\hline
\end{tabular}

Table 2. Microstructural features in high strength aluminium alloys

\section{AA2xxx}

The AA2xxx series of alloys are among the most complicated to analyse. While there have been several reports of the compositions of different phases within this group, most have focused on the legacy alloy AA2024-T3, which, unfortunately, is one of the most complex of the 2xxx series of alloys. Perhaps one of the better known of these works was published in 1950 by Phragmen (Phragmen 1950). He examined all the binary, ternary, quaternary quinternary and senary compositions in order to under stand the IM particles in AA2024. Unfortunately the classification of these particles relied heavily on metallographic techniques (etches) and optical microscopy meaning that assignment of IM particles was, in many cases made on appearance and not on composition. These types of studies, however, 
form the basis for modern assignment of IM particles. From the perspective of obtaining the desired mechanical properties at the nanometer scale, characterisation has focused on the evolution of the alloy microstructure. Corrosion initiation, however, is much more closely related to the large constituent particles whose compositions are based on major alloying elements. Corrosion propagation involves all scales of the alloy microstructure.

Copper and magnesium are the two major alloying additions in AA2xxx wrought alloys and because of the $\mathrm{Cu}$, this series is less resistant to corrosion than alloys of other series. Much of the thin sheet made of these alloys is produced as an Al-clad composite, with a relatively pure aluminium alloy as the outer layer, but thicker sheet and other products in many applications have no protective cladding. Electrochemical effects on corrosion can be stronger in these alloys than in alloys of many other types because of two factors: larger variations in electrochemical activity with variations in amount of copper in solid solution and, under some conditions, the presence of non-uniformities in solid solution concentration. The decrease in resistance to corrosion with increasing copper content is exacerbated by the corrosion process itself by the formation of minute copper particles or films deposited on the alloy surface as a result of corrosion.

To begin to understand the microstructure and its influence on corrosion it is important to know compositions of second phase intermetallic particles. However, the characterisation of these IM particles in the corrosion literature is poor with virtually no studies that relate composition with crystal structure. Hence, there is a need for a detailed identification system which links compositional variation within IM particles, with crystallography and electrochemical character. The objective is to move from a purely phenomenological description of corrosion to a level of understanding where the corrosion process can be predicatively modelled. This level of understanding is primarily aimed at developing structural health management algorithms for maintenance management and several approaches to this are already outlined in the literature (Hughes, Hinton et al. 2007; Cavanaugh, Buchheit et al. 2010; Ralston, Birbilis et al. 2010), (Trueman 2005). The determination of appropriate metrics for the compositional and electrochemical characteristics for IM particles is not so straight forward and is addressed below.

IM particles in AA2024-T3 are currently identified and categorised by one or a mixture of the following:

i. composition

ii. electrochemistry

ii. crystallography

iv. shape

Composition and electrochemistry are the most useful categories for corrosion studies and the convergence of these two systems is desirable and has already been achieved for alloys with simpler microstructure. This means that in many alloys a particular composition can be associated with a specific electrochemical behaviour. This is not the case, for example, in AA2024-T3 where there is large compositional variation as described below. The crystallography of IM phases is not so useful in corrosion studies since it is likely that specific crystal structures do not have a one to one relationship with either composition or the electrochemistry in AA2024-T3. What generally happens in the corrosion literature is that once the composition of an IM particle is determined then the particle is assigned a standard stoichiometry which is derived from crystallographic studies. So there is an assumption that a particular composition has a specific crystallographic structure which may not be valid. For example, Wei and coworkers (Gao, Feng et al. 1998; Wei, Liao et al. 1998) used TEM to 
study IM particles in AA2024-T3 and AA7075-T6 and found that compositions containing $\mathrm{Al}, \mathrm{Cu}, \mathrm{Fe}, \mathrm{Mn}$ and $\mathrm{Si}$, had a rhomohedral structure which did not match the hexagonal structure previously reported for particles of this type for example $\mathrm{Al}_{8} \mathrm{Fe}_{2} \mathrm{Si}$ or $\mathrm{Al}_{10} \mathrm{Mn}_{3} \mathrm{Si}$. Classifying IM particles by shape is used both in metallurgy and corrosion. It is commonly used to distinguish between phase that contain Al-Cu-Fe-Mn-Si which tend to be angular and $S\left(\mathrm{Al}_{2} \mathrm{CuMg}\right)$ and $\theta\left(\mathrm{Al}_{2} \mathrm{Cu}\right)$ phase which tend to be rounded. This distinction is alluded to in standard texts describing the microstructure of AA2024-T3 (Hatch 1984). This is the least reliable method of identification since it has recently been demonstrated that $\mathrm{Al}_{7} \mathrm{Cu}_{2} \mathrm{Fe}$ also has a rounded structure and is a similar size to $S$ and $\theta$-phase constituent particles suggesting that assignement by shape could easily lead to mis-identification.

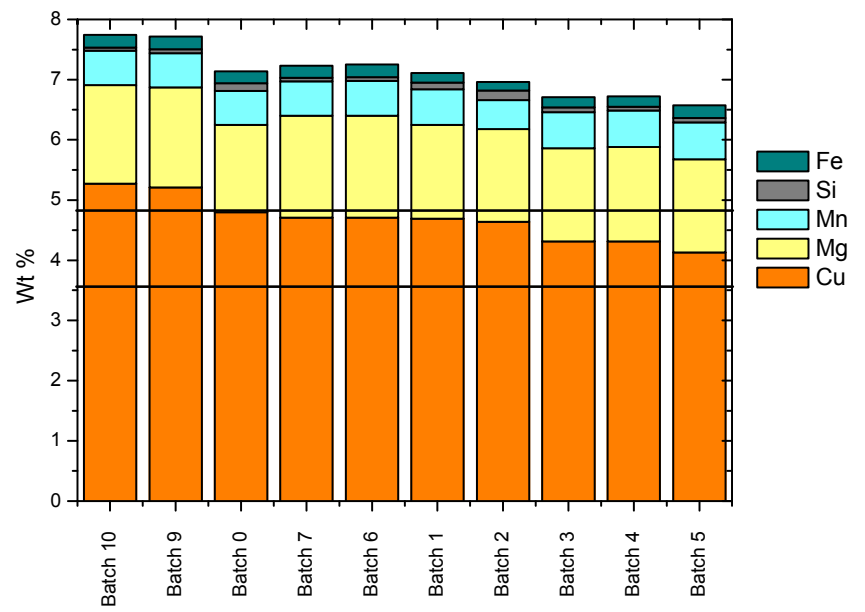

Fig. 4. Analyses in wt \% for $\mathrm{Cu}, \mathrm{Mg}$, Mn, Si and Fe in ten different batches of AA2024-T3(51) purchased over the period 1995 to late 2000

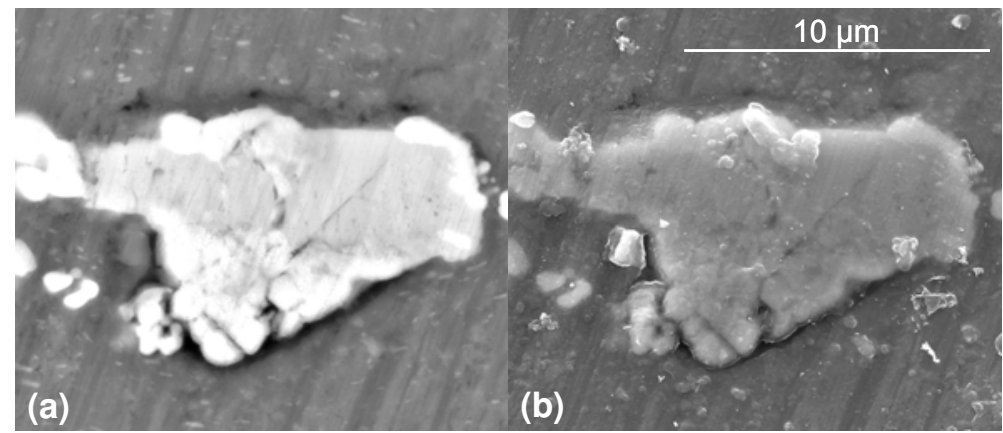

Fig. 5. (a) backscattered and (b) secondary electron images of an IM particle with compositional domains. Corroded in $0.1 \mathrm{M} \mathrm{NaCl}$ for 30 minutes at room temperature

To understand the complexity of the AA2024-T3 microstructure we begin with the compositional variation between several batches of sheet product (Figure 4). The major alloying components in the $2 \times x \times$ series are $\mathrm{Cu}$ and $\mathrm{Mg}$ and they generally have similar mole 
fractions. $\mathrm{Cu}, \mathrm{Mn}$ and $\mathrm{Mg}$ have specified compositional bands and the bands for $\mathrm{Cu}$ are superimposed on Figure 4. Clearly, most batches fall within specification, although two batches breach the upper specification limit by 0.3 to $0.4 \mathrm{wt} \%$. The IM particles are formed from these elements and the variation in composition from batch to batch manifests itself in compositional variation of the IM particles. The origin of this variation is described above and is related to the source material.

The reason why compositional variation from batch to batch represents a difficulty is that the transition elements can be substitutional in many intermetallics. For example Ayer et al. (Ayer, Koo et al. 1985) found $\mathrm{Zn}$ and $\mathrm{Ni}$ in $\mathrm{Al}_{7} \mathrm{Cu}_{2} \mathrm{Fe}$, and Gao et al. (Gao, Feng et al. 1998) found considerable compositional variation within a phase nominated as $(\mathrm{Fe}, \mathrm{Mn})_{\mathrm{x}} \mathrm{Si}(\mathrm{Al}, \mathrm{Cu})_{\mathrm{y}}$ with some particles containing mainly $\mathrm{Fe}$ and $\mathrm{Cu}$ with small amounts of $\mathrm{Mn}$ and others had significant $\mathrm{Mn}$ and Si; similar results were reported by Boag et al.(Boag, Taylor et al. 2010). Gao et al. (Gao, Feng et al. 1998) even found small amounts of $\mathrm{Cr}$ and $\mathrm{Zn}$ in $\mathrm{Al}_{2} \mathrm{CuMg}$. These variations can make it difficult to classify the particles on the basis of composition alone. In addition to composition variation, many individual IM particles often contain compositional domains within the particle. Figure 5 shows backscattered and secondary electron images of an IM particle with different composition domains. The bright regions in the backscatter images are $\mathrm{Cu}$ and $\mathrm{Fe}$ rich as described above whereas the darker parts of the IM particle contain more $\mathrm{Mn}$ and $\mathrm{Si}$. It is not know whether these domains have different crystal structures. The dark band around the bottom of the IM particle represents the beginning of a form of corrosion called trenching which is often observed around cathodic IM particles. It is clear that this corrosion has initiated in the matrix adjacent to the $\mathrm{Cu}$ and Fe rich part of the IM particle indicating greater electrochemical activity of this part of the particle.

From the literature, standard texts such as Hatch (Hatch 1984) lists the IM particles in AA2024-T3 and AA7075-T6 as presented in Table 3. These compositions are derived from metallurgical studies. At the top of the Table are the "as-cast" compositions and in the bottom the wrought compositions. According to these standard texts, heat treatment dissolves much of the $\mathrm{Al}_{2} \mathrm{Cu}$ and $\mathrm{Al}_{2} \mathrm{CuMg}$ whereas all Fe-containing IM particles convert to $\mathrm{Al}_{7} \mathrm{Cu}_{2} \mathrm{Fe}$. Thus the wrought composition contains the IM particles listed in Table 3. Compositional analyses in several other studies have some overlap with the composition of phases (based on stoichiometry) listed in Table 3. Compositional analyses from the three most comprehensive studies in the literature are presented Tables 4 to 6 .

\begin{tabular}{|c|c|c|}
\hline Treatment & \multicolumn{2}{|l|}{ Phases } \\
\hline & AA2024-T3 & AA7075-T6 \\
\hline $\begin{array}{l}\text { Cast } \\
\text { Ingot formation }\end{array}$ & $\begin{array}{l}\mathrm{Mn}, \mathrm{Fe})_{3} \mathrm{SiAl}_{12} \\
\mathrm{Mg}_{2} \mathrm{Si} \\
\mathrm{Al}_{2} \mathrm{Cu}(\theta-\text { phase }) \\
\mathrm{Al}_{2} \mathrm{CuMg} \text { (s-phase) } \\
\mathrm{Al}_{3}(\mathrm{Fe}, \mathrm{Mn}) \\
\mathrm{Al}_{6}(\mathrm{Fe}, \mathrm{Mn})\end{array}$ & $\begin{array}{l}(\mathrm{Fe}, \mathrm{Cr})_{3} \mathrm{SiAl}_{12} \\
\mathrm{Mg}_{2} \mathrm{Si} \\
\mathrm{Zn}_{2} \mathrm{Mg}\left((\mathrm{Zn}, \mathrm{Cu}, \mathrm{Al})_{2} \mathrm{Mg}\right)\end{array}$ \\
\hline Wrought & $\begin{array}{l}\mathrm{A}_{12} \mathrm{CuMg} \\
\text { Unreacted }(\mathrm{Mn}, \mathrm{Fe})_{3} \mathrm{SiAl}_{12} \\
\mathrm{Al}_{7} \mathrm{Cu}_{2} \mathrm{Fe} \\
\mathrm{Al}_{20} \mathrm{Mn}_{3} \mathrm{Cu}_{2} \text { (Dispersoid) }\end{array}$ & $\begin{array}{l}(\mathrm{Fe}, \mathrm{Cr})_{3} \mathrm{SiAl}_{12} \\
\mathrm{Al}_{7} \mathrm{Cu}_{2} \mathrm{Fe} \\
\mathrm{Al}_{18} \mathrm{Mg}_{3} \mathrm{Cr}_{2} \text { (Dispersoid) }\end{array}$ \\
\hline
\end{tabular}

Table 3. Typical breakdown of constituent particles in AA2024-T3 and AA7075-T6 


\begin{tabular}{|l|l|l|}
\hline Particle Type & Measured Stoichiometry & Other elementse \\
\hline $\mathrm{Al}_{2} \mathrm{CuMg}$ & $\mathrm{Al}_{51.62} \mathrm{Cu}_{24} \mathrm{Mg}_{23.52}$ & $\mathrm{Fe}(0.08), \mathrm{Mn}(0.05), \mathrm{Cr}(0.09) \mathrm{Zn}(0.75)$ \\
\hline $\mathrm{Al}_{2} \mathrm{CuMg}(\mathrm{EPMA})$ & $\mathrm{Al}_{52.8} \mathrm{Cu}_{24.5} \mathrm{Mg}_{22.7}$ & - \\
\hline $\mathrm{Al}{ }_{2} \mathrm{Cu}$ & $\mathrm{Al}_{62.98} \mathrm{Cu}_{33.83} \mathrm{Mg}_{2.82}$ & $\mathrm{Fe}(0.11), \mathrm{Mn}(0.04), \mathrm{Cr}(0.17) \mathrm{Ni}(0.06)$ \\
\hline$(\mathrm{Al}, \mathrm{Cu})_{\mathrm{y}} \mathrm{Si}(\mathrm{Fe}, \mathrm{Mn})_{\mathrm{x}}$ & $\mathrm{Al}_{67.6} \mathrm{Cu}_{3.36} \mathrm{Fe}_{14.89} \mathrm{Mn}_{6.87} \mathrm{Si}_{6.27}$ & $\mathrm{Mg}(0.43)$ \\
\hline
\end{tabular}

Table 4. Composition of IM particles in AA2024-T3 determined by Gao et al. (Gao, Feng et al. 1998)

Wei and co-workers(Gao, Feng et al. 1998) identified S-phase, $\theta$-phase and the remainder were categorised as $(\mathrm{Fe}, \mathrm{Mn})_{\mathrm{x}} \mathrm{Si}(\mathrm{Al}, \mathrm{Cu})_{\mathrm{y}}$ indicating no $\mathrm{Al}_{7} \mathrm{Cu}_{2} \mathrm{Fe}$. Electron diffraction of these phases found an unidentified rhombohedral structure and particles with the general composition of $(\mathrm{Fe}, \mathrm{Mn})_{x} \mathrm{Si}(\mathrm{Al}, \mathrm{Cu})_{y}$ were reported as variants of $\mathrm{Al}_{8} \mathrm{Fe}_{2} \mathrm{Si}$ or $\mathrm{Al}_{10} \mathrm{Mn}_{3} \mathrm{Si}$. Buchheit et al.(Buchheit, Grant et al. 1997) performed an electron microprobe analysis of 652 particles and identified S-phase and a range of phases containing $\mathrm{Al}, \mathrm{Cu}, \mathrm{Fe}$ and $\mathrm{Mn}$ as listed in Table 5. In the most recent study, Boag et al. (Boag, Hughes et al. 2009), examined around 82,000 compositional domains in 18,000 IM particles and identified the compositions in Table 6. An example of these compositional domains within IM particles is shown in Figure 6. $(\mathrm{Al}, \mathrm{Cu})_{21}(\mathrm{Mn}, \mathrm{Fe})_{4} \mathrm{Si}$ are widespread in the alloy and were assigned to the $(\mathrm{Fe}, \mathrm{Mn})_{\mathrm{x}} \mathrm{Si}(\mathrm{Al}, \mathrm{Cu})_{\mathrm{y}}$ phase identified by Wei and co-workers. The S-phase and $\theta$-phase predominantly occur as domains within individual, but composite particles. $\mathrm{Al}_{7} \mathrm{Cu}_{3} \mathrm{Fe}$, in most instances, are a third group of particle and have domains, generally within their centre of $\mathrm{Al}_{10}(\mathrm{Cu}, \mathrm{Mg})$. A periphery phase was observed around $\mathrm{S} / \theta$ phase composite particles, which appeared to coincide with a precipitate free zone (Boag 2009; Boag, Hughes et al. 2009). There was also a periphery phase surrounding many particles.

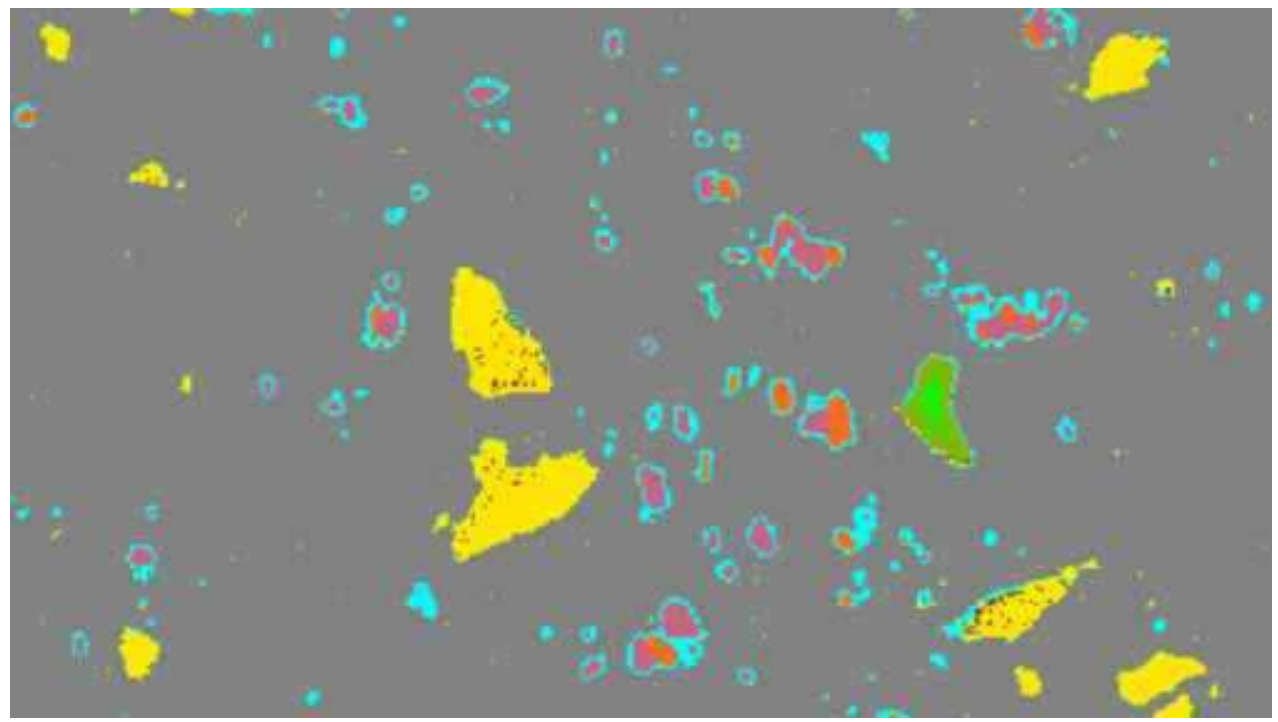

Fig. 6. Microprobe image IM particles in AA2024-T3 showing compositional domains. $\square=$ $(\mathrm{Al}, \mathrm{Cu})_{21}(\mathrm{Mn}, \mathrm{Fe})_{4} \mathrm{Si}, \square=\mathrm{Al}_{2} \mathrm{CuMg}, \square=\mathrm{Al}_{2} \mathrm{Cu}, \square=\mathrm{Al}_{7} \mathrm{Cu}_{3} \mathrm{Fe}, \square=\mathrm{Al}_{10}(\mathrm{Cu}, \mathrm{Mg}), \square=$ $\mathrm{Al}_{3}(\mathrm{Cu}, \mathrm{Fe}, \mathrm{Mn})$ 
What is clear from these studies is that there is no definitive composition for particles that contain $\mathrm{Al}, \mathrm{Cu}, \mathrm{Mn}, \mathrm{Fe}$, and $\mathrm{Si}$ (with small additions of other elements) and it is clear from observations such as those in Figure 5 that these regions of compositional variation have different electrochemical activity. In addition to the compositional variation there is evidence of considerable microstructural variations within the compositional field defined for AA2024-T3. For example $\theta$-phase has been reported recently in studies of AA2024-T3, whereas no $\theta$-phase was detected by Buchheit et al. (Buchheit, Grant et al. 1997) and Hughes and co-workers have examined different batches of AA2024-T3 sheet product and detected some batches with only S-phase and some with S-phase/ $\theta$-phase composite particles(Boag, Taylor et al. 2010).

\section{AA7xxx}

In AA7xxx wrought alloy the major alloying element is zinc along with magnesium or magnesium plus copper in combinations that develop various levels of strength. Those containing copper have the highest strengths and have been used as structural materials, primarily in aircraft applications.

\begin{tabular}{|l|c|c|}
\hline Particle Type & Number percent & Area percent \\
\hline $\mathrm{Al}_{2} \mathrm{CuMg}$ & 61.3 & 2.69 \\
\hline $\mathrm{Al}_{3}(\mathrm{Cu}, \mathrm{Fe}, \mathrm{Mn})$ & 12.3 & 0.85 \\
\hline $\mathrm{Al}_{7} \mathrm{Cu}{ }_{3} \mathrm{Fe}$ & 5.2 & 0.17 \\
\hline$(\mathrm{Al}, \mathrm{Cu})_{6} \mathrm{Mn}$ & 4.3 & 0.11 \\
\hline Indeterminate & 16.9 & 0.37 \\
\hline
\end{tabular}

Table 5. Composition of IM particles in AA2024-T3 determined by Buchheit et al. (Buchheit, Grant et al. 1997)

\begin{tabular}{|c|c|c|c|c|}
\hline Phase Label & $\begin{array}{l}\text { Measured } \\
\text { Stoichiometry }\end{array}$ & $\begin{array}{l}\text { Area } \\
\text { (\% of total) }\end{array}$ & $\begin{array}{l}\text { Particle Density } \\
\left(\text { number } / \mathrm{cm}^{2}\right)\end{array}$ & $\begin{array}{l}\text { Mean Particle } \\
\text { Diameter }(\mu \mathrm{m})\end{array}$ \\
\hline Matrix & $\mathrm{Al}_{96} \mathrm{Cu}_{2} \mathrm{Mg}_{5}$ & Residual & - & \\
\hline$(\mathrm{Al}, \mathrm{Cu})_{2} 1(\mathrm{Mn}, \mathrm{Fe})_{4} \mathrm{Si}$ & $\mathrm{Al}_{77} \mathrm{Cu}_{5} \mathrm{Mn}_{5} \mathrm{Fe}_{10} \mathrm{Si}_{4}$ & 0.742 & 22052 & 5.19 \\
\hline $\mathrm{Al}_{2} \mathrm{CuMg}$ & $\mathrm{Al}_{61} \mathrm{Cu}_{20} \mathrm{Mg}_{15}$ & 0.381 & 22412 & 4.52 \\
\hline $\mathrm{Al}_{7} \mathrm{Cu}_{3} \mathrm{Fe}$ & $\mathrm{Al}_{70} \mathrm{Cu}_{18} \mathrm{MnFe}_{6}$ & 0.089 & 22076 & 1.84 \\
\hline$(\mathrm{Al}, \mathrm{Cu})_{93}(\mathrm{Fe}, \mathrm{Mn})_{5}(\mathrm{Mg}, \mathrm{Si})_{2}$ & $\mathrm{Al}_{90} \mathrm{Cu}_{3} \mathrm{MgMn}_{2} \mathrm{Fe}_{3} \mathrm{Si}$ & 0.252 & 140296 & 1.46 \\
\hline $\mathrm{Al}_{10}(\mathrm{Cu}, \mathrm{Mg})$ & $\mathrm{Al}_{90} \mathrm{Cu}_{7} \mathrm{Mg}_{2}$ & 0.983 & 81856 & 5.38 \\
\hline $\mathrm{Al}_{3}(\mathrm{Cu}, \mathrm{Fe}, \mathrm{Mn})$ & $\mathrm{Al}_{73} \mathrm{Cu}_{11} \mathrm{Mn}_{4} \mathrm{Fe}_{10} \mathrm{Si}$ & 0.062 & 17728 & 1.97 \\
\hline Periphery & $\mathrm{Al} 81 \mathrm{Cu}_{12} \mathrm{Mg}_{4} \mathrm{MnFe}$ & 0.018 & 3868 & 2.26 \\
\hline $\mathrm{Al}_{2} \mathrm{Cu}$ & $\mathrm{Al}_{70} \mathrm{Cu}_{27}$ & 0.298 & 17568 & 4.60 \\
\hline Total & & $2.83 \%$ & 320,000 & $\mathrm{~N} / \mathrm{A}$ \\
\hline
\end{tabular}

Table 6. Composition of IM particles in AA2024-T3 determined by Boag et al. (Boag, Hughes et al. 2009)

The AA7xxx wrought alloys are anodic to AA1xxx wrought aluminium and to other aluminium alloys. Resistance to general corrosion of the copper-free wrought AA7xxx alloys is good, approaching that of the wrought AA3xxx, AA5xxx and AA6xxx alloys. The coppercontaining alloys of the AA7xxx series, such as 7049, 7050, 7075, and 7178 have lower resistance to general corrosion than those of the same series that do not contain copper 
(Meng and Frankel 2004). All AA7xxx alloys are more resistant to general corrosion than AA2xxx alloys, but less resistant than wrought alloys of other groups. The AA7xxx series alloys are among the aluminium alloys most susceptible to SCC and $\mathrm{Cu}$ is beneficial from the standpoint of resistance to SCC.

While the total weight of alloying components in AA7075-T6 is higher than AA2024-T3 by around 1 to $2 \%$ the microstructure tends to be simpler, in terms of the number and identification of IM particle types. Hardening precipitates are generally of the family $\eta$ phase $\left(\mathrm{Zn}_{2} \mathrm{Mg}\right)$ and dispersoids are of the composition $\mathrm{Al}_{20} \mathrm{Cu}_{2} \mathrm{Mn}_{3}$ and $\mathrm{Al}_{18} \mathrm{Mg}_{3} \mathrm{Cr}_{2}$. Like AA2024-T3 reports of constituent particle compositions vary. Gao et al.(Gao, Feng et al. 1998) report two phases: $\mathrm{Al}_{23} \mathrm{Fe}_{4} \mathrm{Cu}$ and $\mathrm{SiO}_{2}$. However, constituent particles compositions reported by others authors suggest $\mathrm{Al}_{7} \mathrm{Cu}_{2} \mathrm{Fe}, \mathrm{Al}_{2} \mathrm{Zn}, \mathrm{Al}_{3} \mathrm{Zr}$ and $\mathrm{Mg}_{2} \mathrm{Si}$ (Birbilis and Buchheit 2005; Wloka and Virtanen 2008).

\subsection{Clustering}

Clustering of IM particles is an emerging area of importance in understanding pit initiation and stabilisation (Chen, Gao et al. 1996; Park, Paik et al. 1996; Park, Paik et al. 1999), (Ilevbare, Schneider et al. 2004), (Liao, Olive et al. 1998; Schneider, Ilevbare et al. 2004; Harlow, Wang et al. 2006), (Cawley and Harlow 1996; Hughes, Boag et al. 2006; Mao, Gokhale et al. 2006; Hughes, Wilson et al. 2009; Hughes, MacRae et al. 2010). Clustering may be important at several different length scales and perhaps even times scales (for corrosion processes). Clustering at length scales similar to the IM particle size can be attributed to IM particle fracture during mechanical processing and, in some instances to non-equilibrium microstructures. An explanation of IM particle clustering reported for larger scale of a few hundred microns is not clear. A study by Mao et al., (Mao, Gokhale et al. 2006) revealed both short range (size similar to the particle dimensions) and long range (few hundred times the particle size) clustering in AA7075 alloy plate material. Clearly the clustered structures are elongated in the rolling direction and they have a range of different sizes. Hughes and co-workers (Hughes, Boag et al. 2006; Hughes, Wilson et al. 2009; Hughes, Muster et al. 2010) reported significant clustering in AA2024-T3 alloy sheet between phase domains within IM particles, as well as between IM particles themselves. In their study they identified strong clustering behaviour between S-phase and $\theta$-phase, S-phase and the $\mathrm{Al}_{7} \mathrm{Cu}_{2} \mathrm{Fe}$ phase and to a lesser extent between S-phase and IM particles with an average stoichoimetry of $(\mathrm{Al}, \mathrm{Cu})_{21}(\mathrm{Fe}, \mathrm{Mn})_{4} \mathrm{Si}$. In that particular study the microstructure consisted of individual particles which had compositional domains of $S$ and $\theta$, which represented a the highest degree of clustering.

Clustering behaviour has also been reported for a number of other aluminium alloys including AA6061-T6, AA7075-T6 and AA5005 (Cawley and Harlow 1996; Hughes, Boag et al. 2006). Coupling between IM particles types of different electrochemical activity has been observed at stable pit sites and attributed to their initiation (Liao, Olive et al. 1998; Boag, Taylor et al. 2010). On the other hand Wei and co-workers (Chen, Gao et al. 1996; Liao, Olive et al. 1998) and Ilevbare et al. (Ilevbare, Schneider et al. 2004) have concluded that clustering in AA2024-T3 and AA7075-T6 alloys leads to large stable pits, primarily through excessive lateral trenching. Cawley and Harlow (Cawley and Harlow 1996) found that IM particles in AA2024-T3 alloys tended to be clustered whereas the pits tended to be randomly distributed because the spatial relationships between IM particles is lost during excessive corrosion. 
In the studies above, clustering was assessed on a statistical basis to determine the average properties of clusters, i.e. lateral size of the cluster, number of particles, types of particles. This raises an interesting question of how these results should be interpreted for modelling applications. The data reported to date tends to describe average clustering behaviour but severe corrosion events might more appropriately be assigned to the extreme properties of the clusters i.e., the densest collection of particles or the most active collection of particles. In this context Boag et al. (Boag, Taylor et al. 2010) observed that the clusters with the highest density of IM particles were those associated with active corrosion on AA2024-T3. These studies suggest that once average IM properties have been assessed for any particular sample then it might also be necessary to determine extreme values.

To conclude this section, it is evident that the compositions of IM particles in AA2xxx and AA7xxx alloys is extremely varied and not well described by any particular classification system for any particular alloy.

\section{Corrosion and microstructure}

\subsection{Corrosion fundamentals}

Corrosion in aluminium alloys is generally of a local nature, because of the separation of anodic and cathodic reactions and solution resistance limiting the galvanic cell size. The basic anodic reaction is metal dissolution $\left(\mathrm{Al} \rightarrow \mathrm{Al}^{3+}+3 \mathrm{e}^{-}\right)$and the cathodic reactions are oxygen reduction $\left(\mathrm{O}_{2}+2 \mathrm{H}_{2} \mathrm{O}+4 \mathrm{e}^{-} \rightarrow 4 \mathrm{OH}^{-}\right)$and hydrogen reduction $\left(2 \mathrm{H}^{+}+2 \mathrm{e} \rightarrow \mathrm{H}_{2}\right)$ in acidified solution such as in a pit environment as a result of aluminium ion hydrolysis.

It is the interaction between local cathodes and anodes and the alloy matrix that leads to nearly all forms of corrosion in aluminium alloys. These include trenching, intermetallic particle etchout, pitting corrosion, intergranular attack and exfoliation corrosion. Surface and subsurface grain etchout is dictated more by grain energy which is derived from grain defect density as described above. Grain etchout, has a significant role in exfoliation corrosion since the volume of hydrated aluminium oxide generated during dissolution is larger than the original volume of the grain.

Relatively pure aluminium presents excellent corrosion resistance due to the formation of a barrier oxide film that is bonded strongly to its surface (passive layer) and, that if damaged, re-forms immediately in most environments (re-passivation). This protective oxide layer is especially stable in aerated solutions of most non-halide salts leading to an excellent pitting resistance. Nevertheless, in open air solutions containing halide ions, with $\mathrm{Cl}$ - being the most common, aluminium is very susceptible to pitting corrosion. This process occurs, because in the presence of oxygen, the metal is readily polarized to its pitting potential, and, because of the presence of chlorides, forms a very soluble chlorinated aluminium (hydr)oxide that does not allow the formation of a stable oxide on the aluminium surface.

On the other hand, industrial alloys surfaces are almost as heterogeneous materials. The surface of a wrought or cast alloy is likely to contain a either mixed Al-Mg oxide (for alloys with Mg (Harvey, Hughes et al. 2008)) or aluminium oxide, almost regardless of the alloy type. This is primarily because of the heat of segregation of $\mathrm{Mg}$ is high and it has a favourable free energy for the formation of the oxide. Aluminium, readily oxidises both in IM particles as well as from the matrix. If the surface was mechanically undisturbed then this oxide would be relatively protective, However, most real surfaces have some sort of mechanical finishing which results in the formation of the NSDL and shingling. Shingling 
occurs where the alloy matrix is spread across the surface including IM particles since the IM particles are harder than the surrounding matrix and less susceptible to deformation (Zhou 2011). Even on polished surfaces, the matrix and the IM particles rapidly form different oxide structures (Juffs, Hughes et al. 2001; Juffs, Hughes et al. 2002). This is almost certainly due to different chemical environments due to different electrochemical reactions over the IM particles compared to the matrix. Furthermore, the morphology and the oxide are not continuous from the IM particles to the matrix and this represents a significant defect site.

The solution potential of an aluminium alloy is primarily determined by the composition of the aluminium rich solid solution, which constitutes the predominant volume fraction and area fraction of the alloy microstructure. While the solution potential is not affected significantly by second phase particles of microscopic size, these particles frequently have solution potentials differing from that of the solid solution matrix resulting in local (micro-) galvanic cells, leading to a variety of local types of corrosion, such as pitting, exfoliation etc. Since most of the commercial aluminium alloys contain additions of more than one type of alloying element, the effects of multiple elements on solution potential are approximately additive. The amounts retained in solid solution, particularly for more highly alloyed compositions, depend on production and thermal processing so that the heat treatment and other processing variables influence the final electrode potential of the product.

Solution potential measurements are useful for the investigation of heat treating, quenching, and aging practices, and they are applied principally to alloys containing copper, magnesium, or zinc. By measuring the potentials of grain boundaries and grain bodies separately, the difference in potential responsible for local types of corrosion such as intergranular corrosion, exfoliation, and stress corrosion cracking (SCC) can be quantified (Guillaumin and Mankowski 1999; Zhang and Frankel 2003). Solution-potential measurement of alloys containing copper also show the progress of artificial aging as increased amounts of precipitates are formed and the matrix is depleted of copper. Potential measurements are valuable with zinc-containing (AA7xxx) alloys for evaluating the effectiveness of the solution heat treatment, for following the aging process, and for differentiating among the various artificially aged tempers. These factors can affect corrosion behaviour significantly.

\subsection{Effects of microstructure on corrosion}

From a corrosion perspective, the dominant features of alloy microstructure are the grain structure and the distribution of second phase IM particles including constituent and impurity particles, dispersoids and precipitates. At the largest scale, corrosion is observed around clusters of constituent and impurity particles which results in severe pitting attack (Chen, Gao et al. 1996; Liao, Olive et al. 1998; Boag, Taylor et al. 2010; Glenn, Muster et al. 2011; Hughes, Boag et al. 2011). Attack around isolated intermetallic particles is now relatively well understood and more on this will be said below. Dispersoids and precipitates have electrochemical characteristics that differ from the behaviour of the surrounding alloy matrix, which is the cause of localized forms of corrosion attack that is often termed microgalvanic corrosion; however it is also now appreciated that such a term does not cover the full complexity of corrosion on Al-alloys. For example Figure 7 shows the co-existance of fine precipitates in the matrix with a coarse constituent particle embedded within the low grain. 


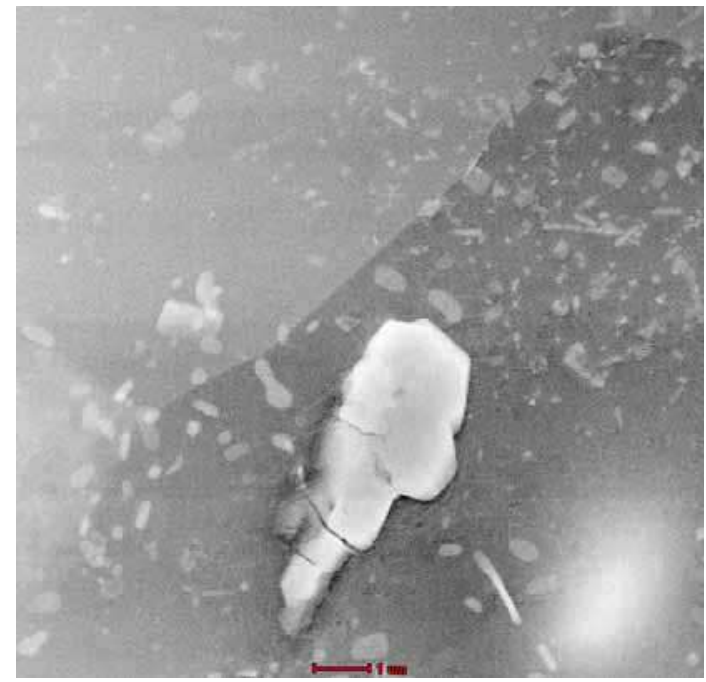

Fig. 7. Dark field scanning transmission electron micrograph of constituent particle coexisting with S-phase $\left(\mathrm{Al}_{2} \mathrm{CuMg}\right)$ precipitate particles in AA2024-T3 sheet

Over the years there have been a number of studies that have assessed the effect of intermetallic particles on the corrosion susceptibility of specific aluminium alloys (Scully, Knight et al. 1993; Birbilis and Buchheit 2005),(Zamin 1981; Mazurkiewicz and Piotrowski 1983; Scully, Knight et al. 1993; Seri 1994). In the 1990s, Buchheit collected the corrosion potential values for intermetallic phases common to aluminium alloys mainly in chloride containing solutions (Buchheit 1995). More recently various groups have focussed on the electrochemical properties of Fe containing intermetallics (Pryor and Fister 1984; Afseth, Nordlien et al. 2002), and Cu containing intermetallics (Searles, Gouma et al. 2001; Birbilis, Cavanaugh et al. 2006; Birbilis and Buchheit 2008) which has been expanded into a comprehensive treatise covering a variety of common intermetallics present in aluminium alloys (Frankel 1998; Birbilis and Buchheit 2005; Birbilis and Buchheit 2008). A summary of the results of these studies is shown below in Table 7 .

\subsection{Second phases}

\subsubsection{Attack around isolated IM particles}

IM particles may be either anodic or cathodic relative to the matrix under any particular set of solution conditions. As a result, two main types of pit morphologies are typically observed around isolated IM particles. Circumferential pits generally appear as trenches around a more or less intact particle and the corrosion attack is mainly in the matrix phase. In the case of clusters, the development of the trench around the cluster is a secondary corrosion reaction following extensive grain boundary attack. Trenching around isolated particles does not lead to more severe corrosion (Chen, Gao et al. 1996; Ilevbare, Schneider et al. 2004; Schneider, Ilevbare et al. 2004; Boag, Hughes et al. 2011). This can be understood in terms of a quantity called the pit stability product first reported by Galvele. This quantity is defined as $i . r$ where $r$ is the depth of the pit and $i$ is the current density. This quantity must be greater than $10^{-2} \mathrm{Acm}^{-1}$ for a nascent pit to be able to grow rapidly enough to establish a long enough diffusion path for an oxygen gradient to be established. This results in oxygen 
reduction near the mouth of the pit at these early stages and an acidic salt solution at the active pit face. Studies have shown that this product is too low for trenching events to develop into stable pits around isolated cathodic particles even for S-phase dealloying (Schneider, Ilevbare et al. 2004).

The second type of pit morphology is due to the selective dissolution of the constituent particle. Pits of this type are often deep and may have remnants of the particle in them. Figure 8 shows a model of dealloying of an S-phase IM particle which leads to a $\mathrm{Cu}$-enriched remnants as well as non-faradaic liberation of the $\mathrm{Cu}$. Under neutral $\mathrm{pH}$ conditions magnesium and aluminium are preferentially dissolved from the $\mathrm{Al}_{2} \mathrm{CuMg}$ phase, leaving a Cu-enriched and high surface area remnant, which then exhibits solution potentials noble to the matrix (Buchheit, Grant et al. 1997). Ultimately, the form that copper takes on the surface is thought to be important in determining the corrosion-performance of alloys such as AA2024. The redistribution of copper has been demonstrated to enhance the kinetics of oxygen reduction processes and negatively affect corrosion. In dealloying from a bulk phase the physical structure of a surface has been predicted by percolation theory to be dependent upon the dissolution rate and concentration of the noble elements in the phase (Sieradzki 1993; Newman and Sieradzki 1994). Rapid dissolution rates lead to more porous network structures, where there is a possibility that unoxidized fragments enriched in the more noble metal will be released into solution, whereas slow dissolution allows surface diffusion and relaxation processes to maintain a stable surface structure. Also, if the noble metal content is sufficient, dealloying will not lead to an isolation of the percolation network. Theory suggests the copper concentration of 25 at \% contained in the $\mathrm{Al}_{2} \mathrm{CuMg}$ phase allows it to dealloy and form both porous copper-rich networks and also to release clusters of both oxidized and unoxidized copper into an electrolyte. It is also noted that hydrodynamic forces may assist in the release of fragments (Buchheit, Martinez et al. 2000; Vukmirovic, Dimitrov et al. 2002; Muster 2009).

\begin{tabular}{|c|c|c|c|c|c|}
\hline \multirow[b]{2}{*}{ Phase } & \multicolumn{5}{|c|}{ Corrosion Potential $\left(\mathrm{mV}_{\mathrm{SCE}}\right)$} \\
\hline & $\begin{array}{c}0.1 \mathrm{M} \mathrm{NaCl} \\
\mathrm{pH} 2.5\end{array}$ & $\begin{array}{c}0.01 \mathrm{M} \mathrm{NaCl} \\
\mathrm{pH} 6\end{array}$ & $\begin{array}{c}0.1 \mathrm{M} \mathrm{NaCl} \\
\text { pH } 6\end{array}$ & $\begin{array}{c}0.6 \mathrm{M} \mathrm{NaCl} \\
\text { pH } 6\end{array}$ & $\begin{array}{c}0.1 \mathrm{M} \mathrm{NaCl} \\
\mathrm{pH} 12.5\end{array}$ \\
\hline $\mathrm{Al}_{3} \mathrm{Fe}$ & -510 & -493 & -539 & -566 & -230 \\
\hline $\mathrm{Al}_{2} \mathrm{Cu}$ & -546 & -592 & -665 & -695 & -743 \\
\hline $\mathrm{Al}_{6} \mathrm{Mn}$ & - & -839 & -779 & -779 & - \\
\hline $\mathrm{Al}_{3} \mathrm{Ti}$ & - & -620 & -603 & -603 & - \\
\hline $\mathrm{Al}_{32} \mathrm{Zn}_{49}$ & - & -1009 & -1004 & -1004 & - \\
\hline $\mathrm{Mg}_{2} \mathrm{Al}_{3}$ & - & -1124 & -1013 & -1013 & - \\
\hline $\mathrm{MgZn}_{2}$ & -1007 & -1001 & -1029 & -1029 & -1012 \\
\hline $\mathrm{Mg}_{2} \mathrm{Si}$ & -1408 & -1355 & -1538 & -1538 & -1553 \\
\hline $\mathrm{Al}_{7} \mathrm{Cu}_{2} \mathrm{Fe}$ & -535 & -549 & -551 & -551 & -594 \\
\hline $\mathrm{Al}_{2} \mathrm{CuMg}$ & -750 & -956 & -883 & -883 & -670 \\
\hline $\mathrm{Al}_{20} \mathrm{Cu}_{2} \mathrm{Mn}_{3}$ & - & -550 & -565 & -565 & - \\
\hline $\mathrm{Al}_{12} \mathrm{Mn}_{3} \mathrm{Si}$ & - & -890 & -810 & -810 & - \\
\hline $\mathrm{Al}-2 \% \mathrm{Cu}$ & - & -813 & -672 & -744 & - \\
\hline $\mathrm{Al}-4 \% \mathrm{Cu}$ & - & -750 & -602 & -642 & - \\
\hline
\end{tabular}

Table 7. Summary of corrosion potentials for intermetallic particles common to Al alloys 


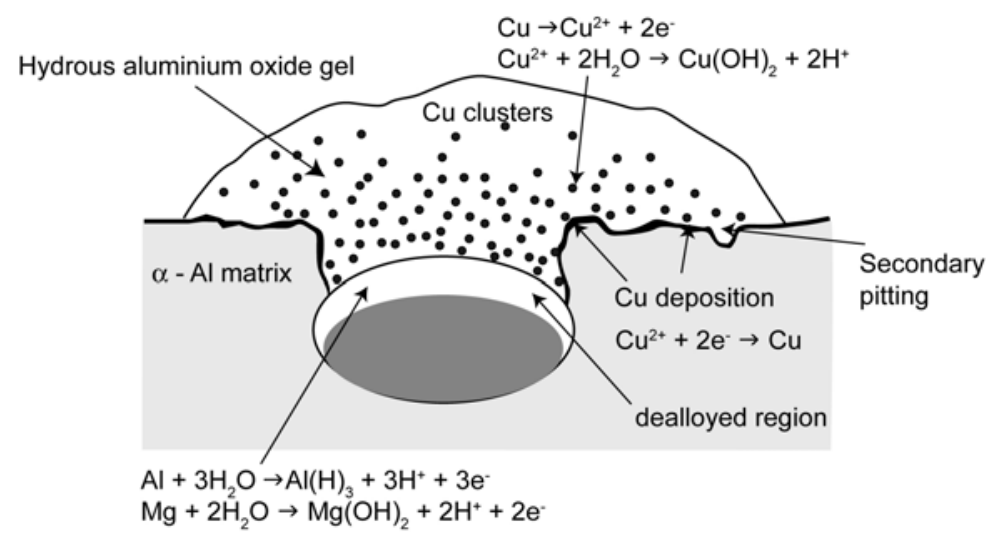

Fig. 8. Schematic of dealloying of $\mathrm{Al}_{2} \mathrm{CuMg}$ phase contained within an aluminium alloy matrix. Anodic polarisation of the particle results in preferential loss of $\mathrm{Al}$ and $\mathrm{Mg}$. $\mathrm{A} \mathrm{Cu}-$ rich network, which coarsens with age, and is susceptible to break-up during hydrodynamic flow, releases small Cu-rich particles (diameter approximately 10-100 nm). The electrically isolated particles are dissolved, making $\mathrm{Cu}$ ions available for replating as elemental $\mathrm{Cu}$ onto cathodic sites. The replated cathodic sites serve as efficient local cathodes that stimulate secondary pitting (after Buchheit et al., 2000)

Localised corrosion activity is, however, a complex phenomenon that is still under active research. Localised corrosion leads to local $\mathrm{pH}$ gradients as recently studied in detail by Ilevbare and Schneider (Ilevbare, Schneider et al. 2004; Schneider, Ilevbare et al. 2004). Enhanced oxygen reduction at cathodic sites generate hydroxyl ions promoting local $\mathrm{pH}$ increases, which can then modify the subsequent rate and morphology of corrosion propagation. Recent work by Boag et al. revealed the timescales on which various forms of attack occurred on isolated IM particles in AA2024-T3. In this study the IM particles in AA2024-T3 were divided into S-phase, $\mathrm{AlCuFeMn}$ phases and $(\mathrm{Al}, \mathrm{Cu})_{\mathrm{x}}(\mathrm{Fe}, \mathrm{Mn})_{\mathrm{y}} \mathrm{Si}$ since these compositions appeared to have separated timescales for attack (Figure 9). These compositions follow the electrochemical activity and provide one method for categorising the IM particles which brings together composition and electrochemistry. Whether this is sufficient for modelling purposes remains to be answered since it does not distinguish, for example, between compositional domains within the one particle that have different corrosion activities as seen in Figure 5. With respect to Figure 9, attack began at the S-phase particles which underwent dealloying indicating anodic behaviour, but then switched to trenching indicating active cathodic behaviour. This was followed by trenching around $\mathrm{AlCuFeMn}$ particles after 30 minutes and finally by trenching around $(\mathrm{Al}, \mathrm{Cu})_{\mathrm{x}} \mathrm{Si}(\mathrm{Fe}, \mathrm{Mn})_{\mathrm{y}}$ at 120 minutes.

The precise morphology of particle-induced pitting is important for emerging damage accumulation models. For these models to be predictive, it is necessary to develop a comprehensive, self-consistent accounting of this type of pitting. In cases where the electrochemical characteristics of constituent particles have been rigorously characterized, they have been found to have much more complicated behaviour than categorised by simple characterizations like "noble" or "active". In recent years, Buchheit and co-workers have attempted an accounting of such phenomena (Figure 10). In such work, electrochemical 


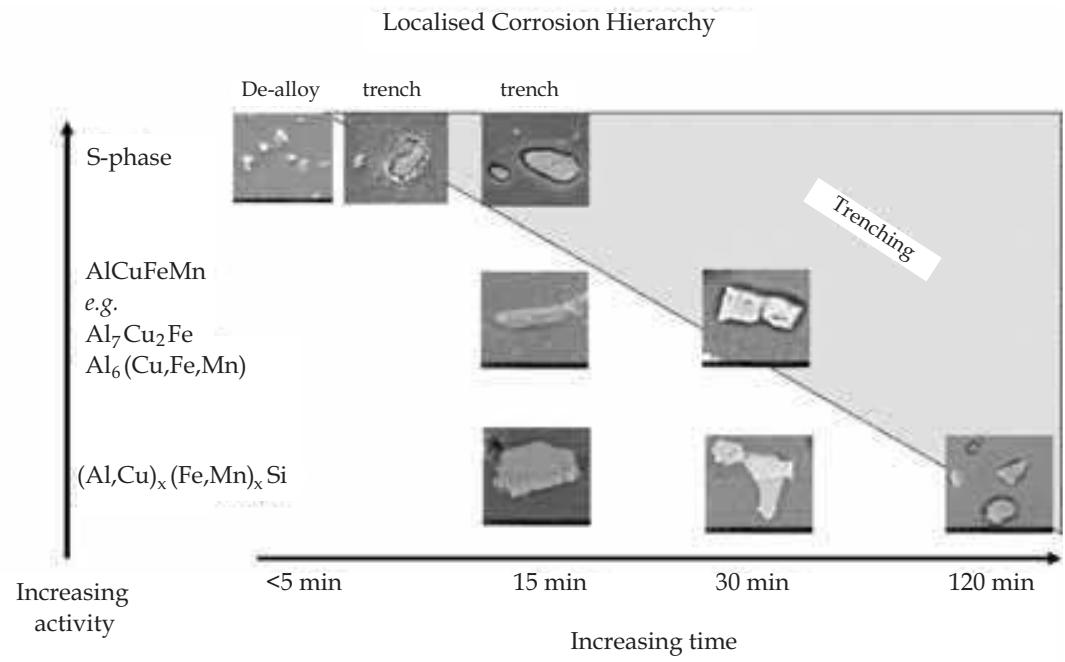

Fig. 9. Hierarchy of localised corrosion attack in $0.1 \mathrm{M} \mathrm{NaCl}$ for AA2024-T3 from Boag et al. (Boag, Hughes et al. 2011)

information relating to microstructural features (from the work used to generate Table 7) was overlaid spatially above real micrographs of AA7075. The data represents the given anodic or cathodic current sustained (at a potential corresponding to the open circuit potential) for each microstructural feature. It is seen that, depending on environment, the currents realised are rather different; and this reconciles very well with 'ground truth' observations from SEM of exposed specimens.

An assumption behind the electrochemical work is that stable pits are on the extreme end (in an extreme value statistics sense) of the metastable pitting events as can be seen in Table 8 for total charge passed, pit stability product and the pit size. There have been other studies that suggest that the current transients are fundamentally different involving activation repassivation events within active pits (Sasaki, Levy et al. 2002). Some studies have also tried to connect phenomenological measurements to the current transients such as through measuring the volume of the trench around an IM particle to the total charge passed. While the total charge passed is similar for both cases, it can be seen (Figure 9) that S-phase dealloying is complete with 5 minutes which means that there are likely to be 75 trenching events occurring simultaneously $/ \mathrm{cm}^{2}$ within the first 5 minutes. However, the frequency of metastable current transients on AA2024-T3 was close to $0.02 \mathrm{~s}$ which is nearly four orders of magnitude smaller. Transient currents associated with $\eta$-phase have been observed in AA7075 (Wloka and Virtanen 2008).

\subsubsection{Corrosion and particles clusters}

As described earlier, the reports of clustering of intermetallic particles in Al-alloys is an emerging area of research in aluminium corrosion. While severe pitting has for many years been attributed to clustering (Chen, Gao et al. 1996; Gao, Feng et al. 1998; Liao, Olive et al. 1998; Schneider, Ilevbare et al. 2004), it is only recently that detailed studies of the connections between clusters and severe pitting have emerged. Part of this work is based on electrochemical studies of current transients measured on corroding surfaces to try to 


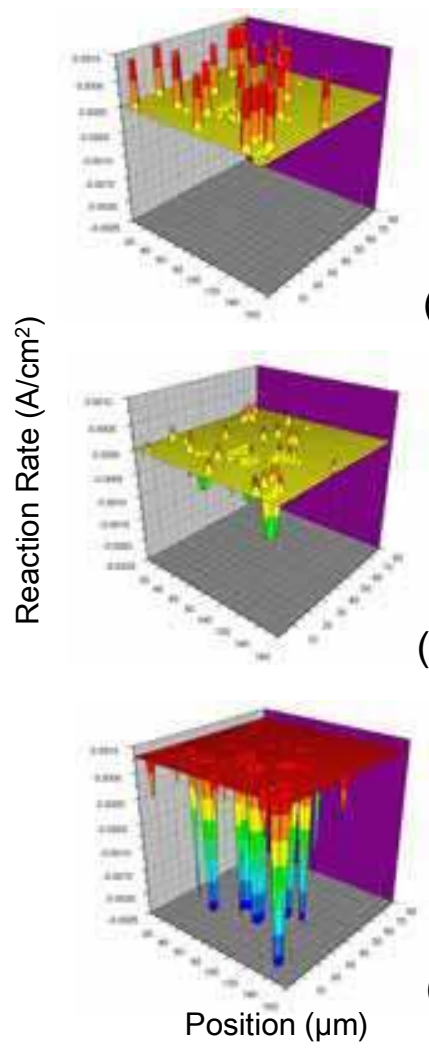

(a)
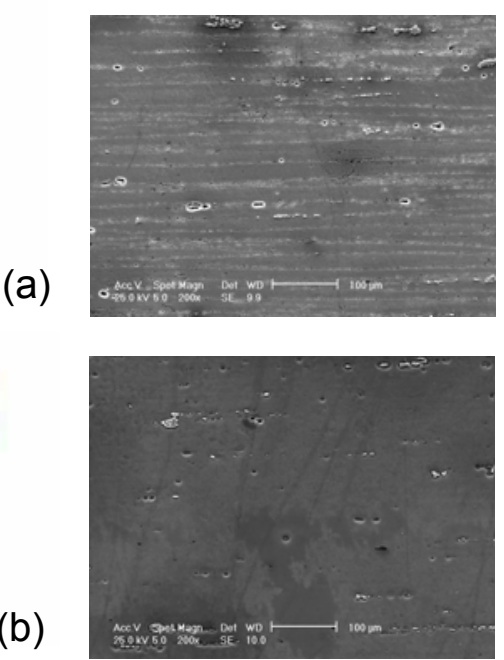

(c)

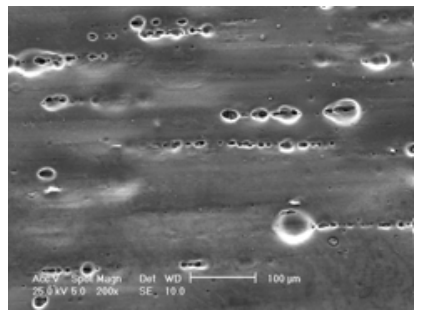

Fig. 10. Left: 3-D representations of the spatial variation in electrochemical reaction rate associated with the 7075 alloy microstructure at a potential of -0.8 Vsce in aerated $0.1 \mathrm{M} \mathrm{NaCl}$ solution at $23^{\circ} \mathrm{C}$ and $\mathrm{pH} 2.5$ (a), pH 6 (b), and pH 12 (c). Right: SE images of AA7075 after a $24 \mathrm{~h}$ exposure under free corrosion conditions in aerated $0.1 \mathrm{M} \mathrm{NaCl}$ solution at $23^{\circ} \mathrm{C}$ and $\mathrm{pH}$ 2.5 (a), pH 6 (b), and pH 12 (c)

establish the boundary between the i.r. product for metastable and stable pits. Such current transients manifest in three ways (i) spontaneous nucleation/passivation events which have very short timescales, (ii) metastable pitting events which have lifetimes up to a several seconds on AA2024-T3 before decaying back to background currents and (iii) stable pitting events, which increase to a transient peak but then decay to a constant current indicating ongoing electrochemical activity. The literature in this area largely comes from a phenomenological or electrochemical perspective, using different terminologies, Table 8 , summaries the activities from these different perspectives.

In terms of the relationship of clustering to stable or severe pitting, it can be seen clearly from Figure 10 that a higher density of IM particles, means a greater level of electrochemical activity. Excessive trenching is the most common explanation for the development of stable pitting from clusters of IM particles. However, in terms of developing models for corrosion initiation, it is important to understand all the pathways to the establishment of stable pits and the mechanisms for those pathways. Recently, Hughes and co-workers reported 


\begin{tabular}{|c|c|c|}
\hline & Metastable & Stable \\
\hline \multicolumn{3}{|l|}{ Phenomenological } \\
\hline Attack descripition & $\begin{array}{l}\text { Pitting (Chen, Gao et al. 1996; Liao, } \\
\text { Olive et al. 1998) } \\
\text { Trenching/S-phase etch [(Kolics, } \\
\text { Besing et al. 2001) (Liao, Olive et al. } \\
\text { 1998; Schneider, Ilevbare et al. } \\
\text { 2004) (Lacroix, Ressier et al. 2008), } \\
\text { (Suter 2001; Blanc, Gastaud et al. } \\
\text { 2003) }\end{array}$ & $\begin{array}{l}\text { Severe pitting (Chen, Gao et al. 1996; Liao, } \\
\text { Olive et al. 1998) } \\
\text { Co-operative corrosion (Hughes, Boag et al. } \\
\text { 2011) }\end{array}$ \\
\hline Attack Type & Individual IM particles & Clusters \\
\hline Attribution & $\begin{array}{l}\text { S-phase dealloying and etchout, } \\
\text { Trenching }\end{array}$ & $\begin{array}{l}\text { Coupling of different IM particle types } \\
\text { Clustered trenching (Liao, Olive et al. 1998) } \\
\text { Corrosion Rings (Liao, Olive et al. 1998) }\end{array}$ \\
\hline Propagation & Virtually none & $\begin{array}{l}\text { GBA, IGA } \\
\text { Subsurface S-phase etchout } \\
\text { Grain etchout }\end{array}$ \\
\hline $\mathrm{H}_{2}$ evolution & None? & $\begin{array}{l}\mathrm{H}_{2} \text { Evolution from within corrosion rings: } \\
\text { It can be continuous or irregular }\end{array}$ \\
\hline \multicolumn{3}{|l|}{ Electrochemical } \\
\hline Total charge $(\mu \mathrm{C})$ & $\begin{array}{l}<13 \text { (Trueman 2005) to } 18 \text { (Pride, } \\
\text { Scully et al. 1994) }\end{array}$ & $\begin{array}{l}>13 \text { (Trueman 2005) to } 18 \text { (Pride, Scully et } \\
\text { al. 1994) }\end{array}$ \\
\hline$i . r$ & $<10^{-2} \mathrm{~A} / \mathrm{cm}$ & $>10^{-2} \mathrm{~A} / \mathrm{cm}$ \\
\hline
\end{tabular}

Table 8. Corrosion Attack on A2024-T3

corrosion initiation within rings of corrosion product on AA2024-T3. Rings of corrosion product were observed a early as 1952 by Pearson et al. in $2 S$ aluminium alloy and developed as early as 15 minutes after immersion. These rings were also observed in the work of Wei's group (Chen, Gao et al. 1996). Hughes et al. reported that the early stages of corrosion within these rings is characterised by $\mathrm{H}_{2}$ evolution and extensive grain boundary attack on the surface which happens prior to, or at the same time as trenching around IM particles (Figure 11). Boag et al. showed that only the most clustered sites on the surface of AA2024-T3 were associated with chloride signals drawing a strong link between clustering and stable pitting. The subsurface attack at these sites was almost exclusively intergranular, penetrating as much as $60 \mu \mathrm{m}$ in 120 minutes exposure to $0.1 \mathrm{M} \mathrm{NaCl}$. The substantial intergranular attack extending deep into the AA2024-T3 and preceded the development of open pits, suggesting that intergranular attack proceeds prior to any substantial grain etchout, even at the surface.

These results suggest that trenching is either a secondary corrosion process or that there are different mechanisms of corrosion initiation which contribute to stable pitting. To further complicate the picture, Zhou, Thompson and co-workers observed that in some alloys there were large $S / \theta$ composite particles and that stable pits were established by direct penetration through the composite particle into the subsurface region of the alloy. This type of attack may be responsible for the widely accepted view that severe pitting can start at Sphase particles. Clearly there may be several avenues to the establishment of stable pits and this is still an area of active research. 


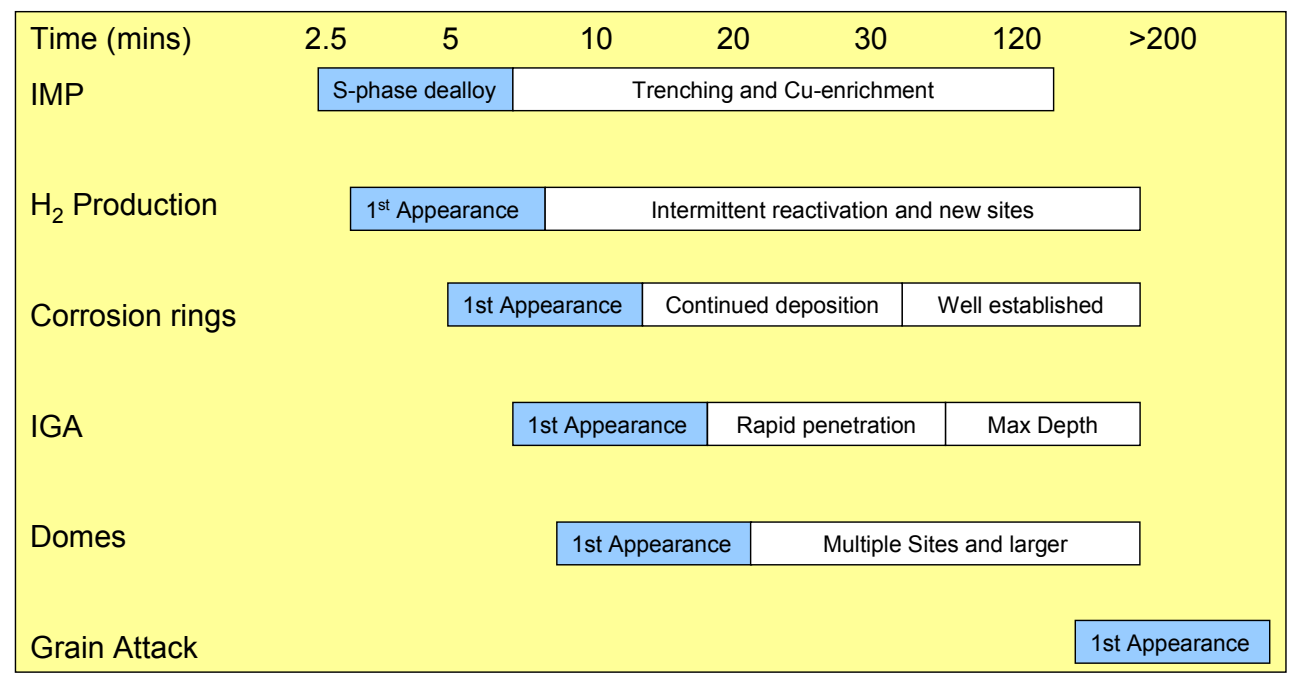

Fig. 11. Stages to stable Pitting after Hughes et al. (Hughes, Boag et al. 2011)

\subsection{Intergranular attack}

Intergranular corrosion is a phenomenon of which the precise mechanisms have been under debate for almost half a century (Hunter 1963). Whilst in a simple view intergranular corrosion can be considered as a special form of microstructurally influenced corrosion, intergranular corrosion can be summarised as a process whereby the grain boundary 'region' of the alloy is preferentially attacked, this is most often because it is anodic to the bulk or adjacent alloy microstructure. Intergranular corrosion can initiate at second phase IM particles in the surface, from pits and from grain boundaries at the surface. Intergranular corrosion penetrates more rapidly than pitting corrosion, and whilst both may have a deleterious effect on corrosion fatigue, the sharper tips produced by intergranular attack are drastic stress concentrators which may reduce the number of cycles to failure.

Corrosion activity may develop because of some heterogeneity in the grain boundary structure. In aluminium-copper alloys, precipitation of $\mathrm{Al}_{2} \mathrm{Cu}$ particles at the grain boundaries leaves the adjacent solid solution anodic and more prone to corrosion. With aluminium-magnesium alloys the opposite situation occurs, since the precipitated phase $\mathrm{Mg}_{2} \mathrm{Al}_{3}$ is less noble than the solid solution. Serious intergranular attack in these two alloys may however be avoided, provided that correct manufacturing and heat treatment conditions are observed.

The distribution of second phase material has a significant influence on the corrosion behaviour of high strength aluminium alloys. Thus, if second phases are located preferentially at grain boundaries, they may promote intergranular corrosion (IGC) due to their compositional, and, hence, electrochemical differences with respect to the adjacent alloy matrix. Further, as a result of precipitation at grain boundaries, the formation of a narrow band on either side of the grain boundary, the precipitation free zone (PFZ), also influences the corrosion behaviour of aluminium alloys since the PFZ is depleted of particular alloying elements. Thus, intergranular corrosion of high strength aluminium alloys is often attributed to compositionally different features at the grain boundary due 
mainly to anodic dissolution of (i) the precipitation free zone where noble alloying elements such as copper are depleted, (ii) anodic second phase precipitates at the grain boundary, or (iii) grain boundaries with segregated alloying elements, such as magnesium, or impurity elements. In the case of the $\mathrm{Al}-\mathrm{Cu}-\mathrm{Mg}$ system, for example, numerous previous studies have suggested that in AA2024 aluminium alloy, when copper-rich precipitates $\left(\mathrm{CuAl}_{2}\right)$ formed at grain boundaries, copper-depleted regions develop adjacent to the boundaries, which are anodic with respect to copper-rich grain boundaries and the grain matrix. A lot of IGC in AA2024 aluminium alloy can be explained as micro-galvanic corrosion of copper-depleted regions driven by cathodic areas of copper-rich grain boundaries and grain matrix. Further, when $\mathrm{S}$ phase $\left(\mathrm{CuMgAl}_{2}\right)$ particles are preferentially precipitated at grain boundaries (typically $<100 \mathrm{~nm}$ ), their anodic nature with respect to the adjacent grain matrix, results in their preferential dissolution.

Not all IGA is so well understood. In AA2024-T3, for example, IGC has been observed in the absence of second phase precipitates, and penetrates up to $60 \mu \mathrm{m}$ within $120 \mathrm{~min}$ of immersion in $0.1 \mathrm{M} \mathrm{NaCl}$ at ambient temperature (Glenn, Muster et al. 2011; Hughes, Boag et al. 2011). While some of the attacked grain boundaries were decorated with $\mathrm{CuAl}_{2}$ or $\mathrm{CuMgAl}_{2}$ precipitates, many grain boundaries that were subject to intergranular attack were not associated with such precipitates, as shown in Figure 12. The TEM image of the corrosion front reveals two parts of a grain boundary, (i) the attacked grain boundary region behind the corrosion front and (ii) the intact grain boundary ahead of the corrosion front. Clearly, precipitation at the grain boundary is absent. Interestingly, although corrosion propagated in a confined region along the grain boundary and the corrosion front followed the grain boundary, corrosion development across the grain boundary is uneven with the interior of grain B being preferentially attacked. Corrosion has developed more than $70 \mathrm{~nm}$ into grain $\mathrm{B}$, with comparably little attack on grain $\mathrm{A}$.

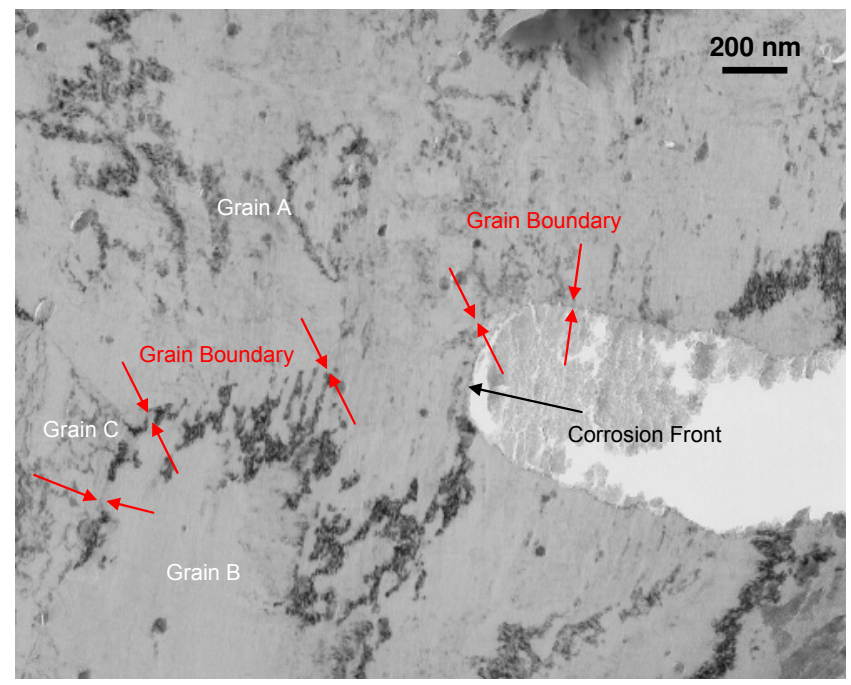

Fig. 12. Transmission electron micrograph of the corrosion front, revealing two parts of a grain boundary: the attacked grain boundary region behind the corrosion front and the intact grain boundary ahead the corrosion front 
Further investigation of the relationship between grain boundary misorientation and its susceptibility to corrosion revealed that the distribution of grain boundary misorientation for the attacked grain boundaries was similar to that in the as-fabricated alloy (Glenn, Muster et al. 2011; Luo to be published). Thus, there must be other factor(s) that influence the corrosion susceptibility of grain boundaries and its zone of influence.

It was revealed using electron backscatter diffraction (EBSD) that grain stored energy plays a significant role in grain boundary attack. The stored energy of a pixel was determined from the misorientation of a pixel from its neighbours within grains. For each pair of pixels, with misorientation above a selected threshold value, a mean boundary energy was calculated using the Read-Shockley equation:

$$
\gamma_{\mathrm{s}}=\gamma_{0} \theta(\mathrm{A}-\ln \theta)
$$

where $\theta$ is the misorientation angle, $\gamma_{0}$ and A are constants. The stored energy of an individual grain/subgrain is determined by averaging the sum of the mean boundary energies over the area of individual grains/subgrains. Then, the spatial distribution of the stored energy is represented as a map, which reflects the average population density of dislocations in individual grains/subgrains.

Figures 13(a) and (b) display a scanning electron micrograph of an AA2024-T3 aluminium alloy surface after immersion in $0.5 \mathrm{M} \mathrm{NaCl}$ solution for $4 \mathrm{~h}$ at ambient temperature and the stored energy map of the same area (Luo to be published). Brighter grains/subgrains have a higher level of stored energy. The corrosion product has been removed from the alloy surface which has been further cleaned using an argon plasma. The attacked local regions along grain boundaries are clearly evident. Comparing the SEM image with the stored energy map of Figure 13(b), it is evident that the regions of attack are located along the grain boundaries that surround grains of relatively high stored energy. Corrosion is not confined within the region immediately adjacent to the grain boundaries, but has developed 1-2 $\mu \mathrm{m}$ into the grains of relatively high stored energy, suggesting that grains with relatively high level of defects are more susceptible to corrosion. The cold work applied to the alloy to achieve the T3 temper resulted in relatively high population density of dislocations in the alloy. The population density of dislocations may vary from grain to grain since grains with different orientations to the rolling direction are subjected to higher levels of strain. Thus, more defects may be introduced in certain grains which have experienced more deformation than other grains. Consequently, some grains are more susceptible to corrosion than other.

Figure 14 displays a backscattered electron micrograph of the cross section of AA2099-T8 aluminium alloy after polarization to $0.824 \mathrm{~V}$ (SCE) in a $0.5 \mathrm{M} \mathrm{NaCl}$ solution. Grain boundary attack is evident to a depth up to $\sim 55 \mu \mathrm{m}$. Individual subgrains were selectively attacked, as indicated by arrows. Some attacked subgrains are close to the surface region, with others being relatively deep into the bulk alloy. It is believed that the subgrains close to the surface region were exposed to the solution earlier than those far away from the surface region. Thus, the attack to certain subgrains within the inner regions suggested that the selective attack is determined by the intrinsic microstructure. EBSD indicates that the attacked sites tend to be the grains of relatively high stored energy compared with the intact grains that are surrounding the attacked grains, suggesting that the grains of high stored energy have relatively high corrosion susceptibility (Luo to be published). 


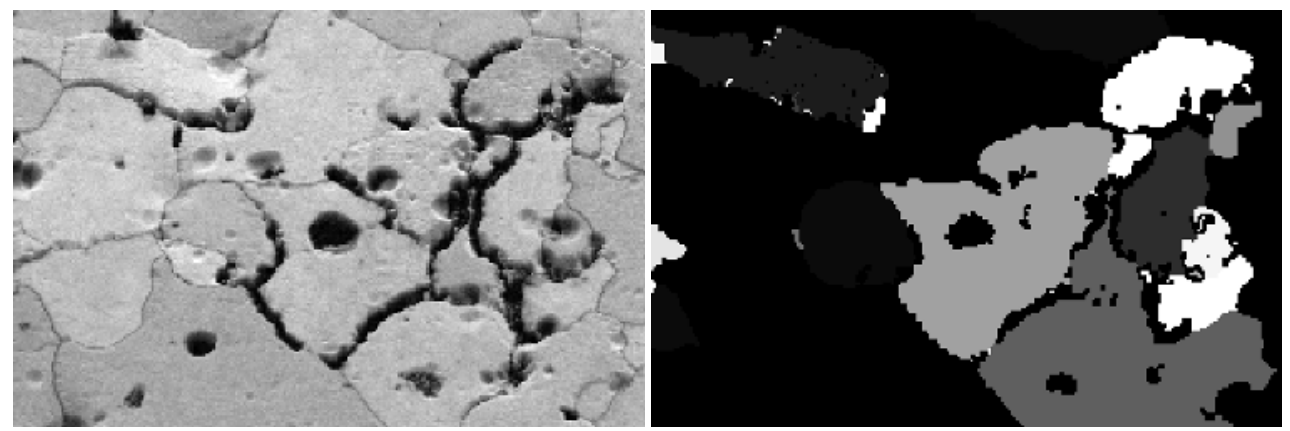

Fig. 13. a) Scanning electron micrograph of the alloy surface after $4 \mathrm{~h}$ of immersion in $0.5 \mathrm{M}$ $\mathrm{NaCl}$ solution at ambient temperature, revealing attacked local regions along grain boundaries; and b) grain stored energy map of the same area as a), obtained with threshold value for misorientation set at 1.3

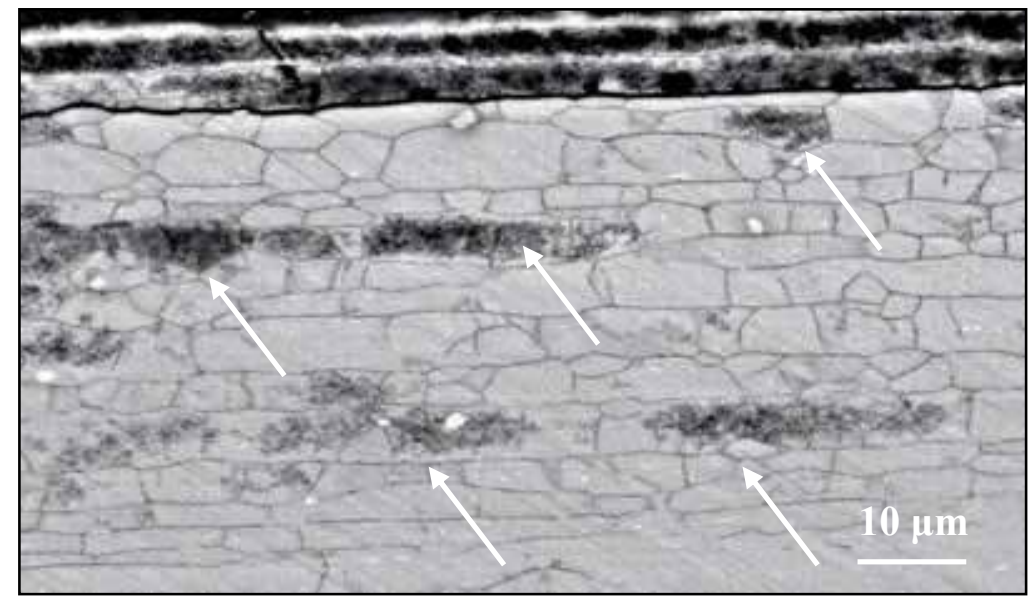

Fig. 14. Scanning electron micrograph of the cross section of AA 2099-T8 aluminium alloy after polarization to $0.824 \mathrm{~V}$ (SCE) in $0.5 \mathrm{M} \mathrm{NaCl}$ solution

In AA7xxx aluminium alloys, when anodic precipitates, such as $\eta-\mathrm{MgZn}_{2}$ phase, are formed at the grain boundaries, then these are relatively active with respect to the grain matrix. IGC occurs, with micro-galvanic coupling between the $\eta-\mathrm{MgZn}_{2}$ phase precipitates and the aluminium matrix adjacent to the particles providing the driving force (Wadeson, Zhou et al. 2006). Again however susceptibility to intergranular corrosion is strongly dependent on the heat treatment condition and its effect on grain boundary solute segregation and the morphology and composition of the grain boundary precipitate and the surrounding alloy matrix. (Knight 2003). The most resistant heat treatments are based on the use of over-aging to the T7 treatment or more complex heat treatments which involve retrogression and reaging to minimise the trade off between alloy strength and intergranular corrosion resistance (Polmear 1995; Davies 1999). The images in Figure 15 help rationalise the origins of intergranular corrosion, in the $\mathrm{Al}-\mathrm{Zn}-\mathrm{Mg}$ system. 
Exfoliation corrosion (Davies 1999; Zhao and Frankel 2007) of aluminium alloys is also frequently due to intergranular corrosion. It generally occurs where the alloy microstructure has been heavily deformed (i.e. by rolling) and the grain structure has been flattened and extended in the direction of working. Intergranular corrosion attack from transverse edges and pits then run along grain boundaries parallel to the alloy surface. Exfoliation is characterised by leafing off of layers of relatively uncorroded metal caused by the swelling of corrosion product in the layers of intergranuar corrosion. Exfoliation is observed on aircraft components, for example, around riveted or bolted components.
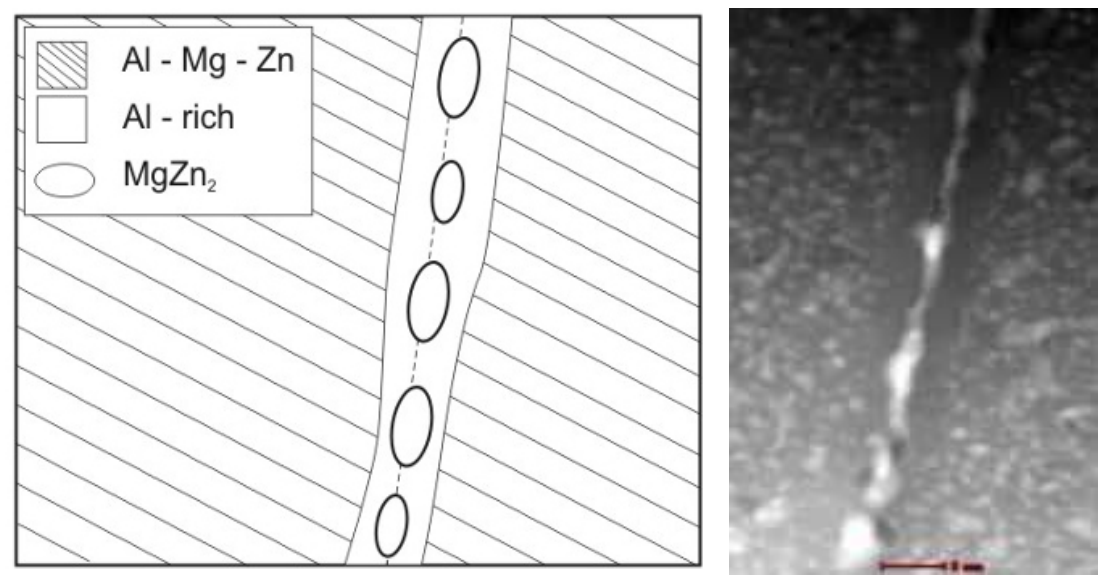

Fig. 15. (a) Schematic of hypothetical grain boundary in an Al-Zn-Mg alloy. This schematic indicates the different chemistry that exists in the grain interior, solute depleted zone (precipitate free zone) and grain boundary precipitates - giving rise to electrochemical heterogeneity localised at the grain boundary region. (b) Conventional bright field TEM image of high angle grain boundary in AA7075-T651, revealing grain boundary precipitates $\left(\mathrm{MgZn}_{2}\right)$ and a distinguishable precipitate free zone

\subsection{Accumulation}

The accumulation of noble metals such as iron and copper at the surface of aluminium alloys is problematic even in the absence of specific intermetallic phases such as $\mathrm{Al}_{2} \mathrm{CuMg}$. The accumulation of $\mathrm{Cu}$ in almost all $\mathrm{Al}$ alloys (even those with low $\mathrm{Cu}$ content) has been an issue in metal finishing for many years and was recently extensively reviewed by Muster et al. (Muster 2009). Copper accumulation at corrosion sites has also been investigated extensively. Vukmirovic et al. (Vukmirovic, Dimitrov et al. 2002) showed that copper accumulation on the surface of AA2024 also arises from the copper in the aluminium solid solution. In a range of corrosive environments, aluminium has been shown to preferentially oxidise, resulting in the build-up of copper within a layer approximately $2-5 \mathrm{~nm}$ thick at the alloy surface (Jung, Dumler et al. 1985; Habazaki, Shimizu et al. 1997). The behaviour of alloying elements in this sense is somewhat dependent upon the Gibbs free energy of oxide formation, which controls the enrichment of elements at the alloy surface and in the surface oxides during corrosion processes. Copper and other more noble elements (i.e. gold) have high Gibbs free energies of oxide formation per equivalent $\left(\Delta \mathrm{G}^{\circ} / \mathrm{n}\right)$ relative to that of 
alumina and therefore show extensive enrichment at the metal/oxide interface. In contrast, elements such as magnesium and lithium for example, have a lower $\Delta G^{\circ} / \mathrm{n}$ value than aluminium and, therefore, are more likely to appear in the oxide or electrolyte solution following corrosion processes (Muster 2009).

In environments where aluminium alloys continually experience anodic dissolution it has been suggested that alloys with a wide range of copper concentrations (0.06 to 26 at \%) can display copper enrichment at the metal-oxide interface (Blanc, Lavelle et al. 1997; Habazaki, Shimizu et al. 1997; Garcia-Vergara, Colin et al. 2004). Once a certain level of enrichment occurs, copper atoms (and most likely other noble alloying elements) are thought to arrange themselves into clusters through diffusion processes and eventually protrude from the alloy surface due to undermining of the surrounding aluminium matrix (Sieradzki 1993; Habazaki, Shimizu et al. 1997). These copper clusters may be released as elemental copper into the oxide layer by being undermined or copper ions may be oxidized directly from the protruding clusters. It has also been demonstrated that the level of copper enrichment is also influenced by grain orientation. In terms of general corrosion performance, the enrichment of copper at the alloy surface is also likely to increase the number of flaws that exist in the aluminium oxide.

\section{Corrosion and protection}

This section covers general approaches to protection of aluminium alloys in view of recent advances in the understanding of alloy microstructure. It includes an overview of pretreatment processes such as anodising, conversion coating and organic coatings (barrier and inhibitor combinations). It will examine recent advances in inhibitor design such as building in multifunctionality and touch on self healing coating systems. Approaches using multifunctionality can target anodic and cathodic reactions more effectively than using individual monofunctional inhibitors.

Standard metal finishing processes, which have been used for many years, are likely to continue to be used into the future unless they contain chemicals that are targeted for replacement such as chromium. The function of these coatings is primarily to provide better adhesion properties for paint coatings and a secondary role is to provide corrosion protection. The general approach for applying these coatings relies on metal finishing treatments (treatment prior to painting involving immersion in acidic and alkaline baths)) with the objective of reducing the heterogeneous nature of the metal surface such as removing the NSDL and second phase particles (Muster 2009). This is achieved in multistep treatment processes for metal protection (Twite and Bierwagen 1998; Buchheit 2003; Muster 2009) as for instance:

1. selective deoxidation (IM particle removal and surface etching);

2. deposition or growth of a manufactured oxide via electrochemical (anodising) or chemical (conversion coating) means;

3. use of an organic coating for specific applications, normally including a primer and a top-coat.

On aluminium, most anodised coating processes produce an outer oxide with a cellular structure on top of a thin barrier layer that provides some protection against corrosion. Inhibitors can be incorporated into the outer porous layer of the anodized layer during formation or as a seal after formation to offer some extra protection upon damage. Chromic 
acid anodizing is one of a number of processes that are available for electrochemical growth of surface protective oxides. More environmentally-friendly alternatives to chromic acid anodizing such as sulfuric, sulfuric-boric, sulphuric-tataric and phosphoric based processes have been available for a long time. There have been a number of recent advances in reducing the energy consumption of anodizing processes as well as improving coating properties. These advances are based on an improved understanding of the alloy microstructure described above and involve selective removal of second phase particles as part of the anodising process.

An alternative approach to anodizing is to precipitate a coating on a surface through chemical means called conversion coatings. For high strength Al-alloys such as $2 \times x x$ and $7 \times x x$ series chromate conversion coating (CCC) is still the preferred process. Replacements for chromate-based conversion coatings include a range of treatments based on selfassembled monolayers, sol-gel chemistries, $\mathrm{Ti} / \mathrm{Z}$ oxyfluorides, rare earth, cobalt, vanadates, molybdates and permanganate processes (Twite and Bierwagen 1998; Buchheit 2003; Kendig and Buchheit 2003). These processes are widely developed for chemically pretreated surfaces that have nearly all the IM particles removed and are not specifically designed to address electrochemical and compositional variations found for a heterogeneous surface such as when the IM phases are present. Work like that in Figure 10 depicting the reaction rate variation across the surface, however, opens an avenue to start designing inhibitors where the initial reaction rate distribution across a surface can be significantly reduced to limit the overall activity of the surface. In this context reaction of inhibitive phases with manufactured IM compounds as well as IM particles within the alloy have been studied for a number of systems (Juffs, Hughes et al. 2001; Juffs 2002; Juffs, Hughes et al. 2002; Birbilis, Buchheit et al. 2005; Scholes, Hughes et al. 2009).

Once the anodised or conversion coating is applied, the surface is ready to receive the organic coating. There are many different types of organic coatings, however because of the focus on $2 x x x$ and $7 x x x$ alloy used in the aerospace industry this section will only deal with that application area. The organic coating system usually consists of a primer and a topcoat. The primer is the main protective layer including corrosion inhibitors that can be released when corrosive species or water reach the metal. From the perspective of providing protection for the underlying aluminium alloy, the inhibitor needs to be available during a corrosion event at a concentration higher than the minimum concentration at which the inhibitor stops corrosion (critical concentration). While this sounds obvious, the critical inhibitor concentration needs to be maintained over many years for structures such as airframes, where maintenance may not be possible in parts of the aircraft because of poor access. The chromate systems itself provide continuous protection and repair to the surface for as long as the dose of chromate remains above the critical concentration. This mechanism of inhibitor release and metal protection is recognized as a self-healing mechanism, since the release of the active species recovers the protective layer on top of the metal.

The search for green inhibitors as replacements for chromate has been driven by legislative imperatives for a number of years. Needless to say, replacement inhibitors do not have the same intrinsic inhibitive power at low solubility as chromate. Thus solubility, inhibitive power and transport within the primer system (which consists of a number of inorganic phases as well as the epoxy) ultimately means that finding a replacement for chromate is difficult. This means that alternatives must be present at higher concentration leading to the use of more soluble compounds and consequently encapsulation as a method of regulating 
the response to external or internal triggers emerges as a prospective way to achieve this objective.

Many current inhibitors are water soluble salts and thus ionic. Consequently, they exist as either anions or cations in solution and perform the single function of anodic or cathodic inhibition. So the simplest improvement to inhibitor design is to increase the functionality by finding compounds which play both a cationic and anionic inhibitive role. A large range of cations including Zn, Ca, and rare earths (Bohm, McMurray et al. 2001; Du, Damron et al. 2001; Kendig and Buchheit 2003; Taylor and Chambers 2008; Muster, Hughes et al. 2009) have been combined with either organic (Osborne, Blohowiak et al. 2001; Sinko 2001) (Voevodin, Balbyshev et al. 2003; Khramov, Voevodin et al. 2004; Blin, Koutsoukos et al. 2007; Taylor and Chambers 2008; Muster, Hughes et al. 2009) or inorganic (oxyanions, carbonates, phosphates, phosphites, nitrates, nitrites, silicate (Bohm, McMurray et al. 2001; Sinko 2001; Blin, Koutsoukos et al. 2007; Taylor and Chambers 2008)) compounds.

Anions with dual functionality, such as some of the transition metal oxyanions which are both oxidants and anions, have been investigated extensively. The oxidizing oyxanions or some organophosphates have some degree of bio-inhibition required for some applications. Substitution of different organophosphates into rare earth-based inhibitors provide versatility in designing inhibitors for specific applications (Birbilis, Buchheit et al. 2005; Hinton, Dubrule et al. 2006; Ho, Brack et al. 2006; Blin, Koutsoukos et al. 2007; Markley, Forsyth et al. 2007; Markley, Hughes et al. 2007; Forsyth, Markley et al. 2008; Deacon, Forsyth et al. 2009; Scholes, Hughes et al. 2009). Thus Ce(di-butyl phosphate) ${ }_{3}$ is a good inhibitor and relatively green whereas Ce(di-phenyl phosphate) $)_{3}$ is also a good inhibitor, but the diphenyl phosphate also has strong bio-inhibition characteristics (García 2011). However, good bio-inhibition usually means that there are increased environmental and health risks. Obviously the number of cathodic and anodic inhibitors means that there is an enormous number of possible combinations, particularly if ternary and quaternary combinations are considered. Hence high-throughput techniques are being used to assess new inhibitor.

As pointed out above, the kinetics of inhibitor release are of the utmost importance since the inhibitor should be available at levels above the critical inhibitor concentration. Optimization of the release kinetics by novel delivery systems become integral to incorporation of new inhibitors.

There are a number of different approaches to release mechanisms for release of healing agents or corrosion inhibitors which can be incorporated into organic coatings. Both mechanical damage and water are triggers for inhibitor release. In the former case mechanical damage breaks capsules containing water soluble inhibitors. In the latter case water dissolves inhibitor directly incorporated in the primer. Droplet formation within defects such as scratches means that the inhibitor is only released when required i.e., when the defect is moist (Furman, Scholes et al. 2006). There is some evidence to suggest that initial high release of inhibitors may be facilitated through atmospheric exposure of the intact paint where penetration of water into the film "prepares" the inhibitor, probably via surface hydrolysis reactions, within the paint, for diffusion and release into the defect (Du, Damron et al. 2001; Furman, Scholes et al. 2006; Scholes, Furman et al. 2006; Souto, González-García et al. 2010). The presence of water in the film allows soluble inhibitor species to be released into the paint system and diffuse to the metal/coating interface to provide in-situ corrosion prevention or repair called pre-emptive healing (Mardel, Garcia et al. 2011) (Zin, Howard et al. 1998; Osborne, Blohowiak et al. 2001). Thus it has been 
demonstrated that water can trigger cerium dibuthylphosphate $\left(\mathrm{Ce}(\mathrm{dbp})_{3}\right)$ release into an epoxy matrix resulting in improved adhesion and resistance to filiform corrosion attack through interfacial modification (Mardel, Garcia et al.).

In terms of delivery systems, hard capsules, which have been used in polymer healing (Dry 1996; White, Sottos et al. 2001; Mookhoek, Mayo et al. 2010) need to be smaller for paint systems particularly in the aerospace industry where coatings are typically $20 \mu \mathrm{m}$ or less (Yin, Rong et al. 2007; Fischer 2010; Mookhoek, Mayo et al. 2010) (Hughes, 2010). In polymer applications, capsules up to a few hundred microns can be accommodated (Yin, Rong et al. 2007; Wu, Meure et al. 2008; Tedim, Poznyak et al. 2010). The concept of encapsulation has already been successfully applied to protective organic coatings under different concepts: i) liquids filling completely the void created by the damage by adopting a bi-component systems where one component is encapsulated and the other distributed in the matrix (Cho, White et al. 2009), or single based components with water reactive oils like linseed and tung oils (Suryanarayana, Rao et al. 2008; Samadzadeh, Boura et al. 2010)and ii) liquids (i.e. silyl esters) forming a hydrophobic and highly adhesive layer covering the metallic surface by reaction with the underlying metal and the humidity in air (Garcia, Fischer et al. 2011). One adaption for capsules is to increase the volume of self healing material by manufacturing rods instead of spheres. Rods with the same cross-sections as spheres can deliver larger volumes of material (Bon, Mookhoek et al. 2007; Mookhoek, Fischer et al. 2009). For inhibitors, their role is to prevent a surface reaction (corrosion) and therefore, the volume of material required is much smaller than that required to actually fill the defect. Consequently, there has been considerable effort looking at "nano-containers" (Voevodin, Balbyshev et al. 2003; Raps, Hack et al. 2009; Tedim, Poznyak et al. 2010).

Water is the most obvious trigger since it can permeate most polymers. $\mathrm{pH}$ variations are more specific and respond to the $\mathrm{pH}$ excursions that occur in corrosion reactions and by an understanding reactions that occur at different sites in the alloy microstructure. The presence of chloride ions (and other anions) within the coating can be used as specific triggers for the release of corrosion inhibitors and uptake of corrodents using anion exchange materials, such as layered double hydroxides (e.g. hydrotalcites) (Tedim, Poznyak et al. 2010) (Bohm, McMurray et al. 2001; Buchheit, Guan et al. 2003; Williams and McMurray 2003; Zheludkevich, Salvado et al. 2005; Mahajanarn and Buchheit 2008). In this context hydrotalcites have been loaded with vanadate, chromate, nitrate and carbonate which exchange for chloride ions and prevent interfacial damage (Bohm, McMurray et al. 2001; Williams and McMurray 2003; Mahajanarn and Buchheit 2008). The incorporation of $\mathrm{Mg}$ particles into paint acts as sacrificial anodes to protect $\mathrm{Al}$ alloys and steels (Battocchi, Simoes et al. 2006).

\section{Conclusions}

The broad range of microstrucutral characteristics associated with the high strength Alalloys have been examined in detail. Perhaps the most attention has been paid to the AA2024-T4 legacy alloy where the microstructure is complicated by the broad compositional variation of second phases, particularly the constituent particles. The role of these features on corrosion has been described and areas where the role of the microstructure is still not clearly understood have been identified and discussed. In the light of a continually emerging understanding of alloy microstructure some general principles of inhibitor design and incorporation into paints systems have been explored. 


\section{References}

Afseth, A., J. H. Nordlien, et al. (2001). "Effect of heat treatment on filiform corrosion of aluminium alloy AA3005." Corrosion Science 43(11): 2093-2109.

Afseth, A., J. H. Nordlien, et al. (2002). "Filiform corrosion of AA3005 aluminium analogue model alloys." Corrosion Science 44(11): 2543-2559.

Allen, C. M., K. A. Q. O'Reilly, et al. (1998). "Intermetallic phase selection in 1XXX Al alloys." Progress in Materials Science 43(2): 89-170.

Ayer, R., J. Y. Koo, et al. (1985). "Microanalytical Study of the Heterogeneous Phases in Commercial Al-Zn-Mg-Cu Alloys." Metallurgical Transactions a-Physical Metallurgy and Materials Science 16(11): 1925-1936.

Birbilis, N. and R. G. Buchheit (2005). "Electrochemical characteristics of intermetallic phases in aluminum alloys - An experimental survey and discussion." Journal of the Electrochemical Society 152(4): B140-B151.

Birbilis, N. and R. G. Buchheit (2008). "Investigation and discussion of characteristics for intermetallic phases common to aluminum alloys as a function of solution $\mathrm{pH}$." Journal of the Electrochemical Society 155(3): C117-C126.

Birbilis, N., R. G. Buchheit, et al. (2005). "Inhibition of AA2024-T3 on a phase-by-phase basis using an environmentally benign inhibitor, cerium dibutyl phosphate." Electrochemical and Solid State Letters 8(11): C180-C183.

Birbilis, N., M. K. Cavanaugh, et al. (2006). "Electrochemical behavior and localized corrosion associated with Al7Cu2Fe particles in aluminum alloy 7075-T651." Corrosion Science 48(12): 4202-4215.

Blanc, C., S. Gastaud, et al. (2003). "Mechanistic studies of the corrosion of 2024 aluminum alloy in nitrate solutions." Journal of the Electrochemical Society 150(8): B396-B404.

Blanc, C., B. Lavelle, et al. (1997). "The role of precipitates enriched with copper on the susceptibility to pitting corrosion of the 2024 aluminium alloy." Corrosion Science 39(3): 495-510.

Blin, F., P. Koutsoukos, et al. (2007). "The corrosion inhibition mechanism of new rare earth cinnamate compounds - Electrochemical studies." Electrochimica Acta 52(21): 62126220 .

Boag, A. (2009). The Relationship Between Microstructure and Stable Pitting Initiation in Aerospace Aluminium Alloy 2024-T3. Melbourne, RMIT. PhD.

Boag, A., A. E. Hughes, et al. (2011). "Corrosion of AA2024-T3 Part I. Localised corrosion of isolated IM particles." Corrosion Science 53(1): 17-26.

Boag, A., A. E. Hughes, et al. (2009). "How complex is the microstructure of AA2024-T3?" Corrosion Science 51(8): 1565-1568.

Boag, A., R. J. Taylor, et al. (2010). "Stable pit formation on AA2024-T3 in a $\mathrm{NaCl}$ environment." Corrosion Science 52(1): 90-103.

Bockris, J. O. M., Reddy, A.K.N., Gamboa-Aldeco, M.E. (2000). Modern Electrochemistry. New York, Kluwer.

Bohm, S., H. N. McMurray, et al. (2001). "Novel environment friendly corrosion inhibitor pigments based on naturally occurring clay minerals." Materials and CorrosionWerkstoffe Und Korrosion 52(12): 896-903.

Bon, S. A. F., S. D. Mookhoek, et al. (2007). "Route to stable non-spherical emulsion droplets." European Polymer Journal 43(11): 4839-4842. 
Buchheit, R. G. (1995). "A Compilation of Corrosion Potentials Reported for Intermetallic Phases in Aluminum-Alloys." Journal of the Electrochemical Society 142(11): 39943996.

Buchheit, R. G., R. P. Grant, et al. (1997). "Local dissolution phenomena associated with S phase (Al2CuMg) particles in aluminum alloy 2024-T3." Journal of the Electrochemical Society 144(8): 2621-2628.

Buchheit, R. G., H. Guan, et al. (2003). "Active corrosion protection and corrosion sensing in chromate-free organic coatings." Progress in Organic Coatings 47(3-4): 174-182.

Buchheit, R. G., Hughes, A.E. (2003). Chromate and Chromate-Free Coatings. Corrosion: Fundamentals, Testing and Protection. C. Moosbrugger. Mterials Park, Oh, USA, ASM International. 13A: 720 -735.

Buchheit, R. G., M. A. Martinez, et al. (2000). "Evidence for Cu ion formation by dissolution and dealloying the $\mathrm{Al} 2 \mathrm{CuMg}$ intermetallic compound in rotating ring-disk collection experiments." Journal of the Electrochemical Society 147(1): 119-124.

Carney, T. J., P. Tsakiropoulos, et al. (1990). "Oxidation and Surface Segregation in Rapidly Solidified Al-Alloy Powders." International Journal of Rapid Solidification 5(2-3): 189-217.

Cavanaugh, M. K., R. G. Buchheit, et al. (2010). "Modeling the environmental dependence of pit growth using neural network approaches." Corrosion Science 52(9): 3070-3077.

Cawley, N. R. and D. G. Harlow (1996). Journal of Material Science 31: 5127-5134.

Chen, G. S., M. Gao, et al. (1996). "Microconstituent-induced pitting corrosion in aluminum alloy 2024-T3." Corrosion 52(1): 8-15.

Cho, S. H., S. R. White, et al. (2009). "Self-Healing Polymer Coatings." Advanced Materials 21(6): 645-+.

Das, S. K. (2006). "Designing Aluminium Alloys for a Recycle-Friendly World." Light Metal Age June.

Davies, J. R. (1999). Corrosion of Aluminium and Aluminium Alloys. Columbus, OH, ASM International.

Deacon, G. B., M. Forsyth, et al. (2009). "Synthesis and Characterisation of Rare Earth Complexes Supported by para-Substituted Cinnamate Ligands." Zeitschrift Fur Anorganische Und Allgemeine Chemie 635(6-7): 833-839.

Dry, C. (1996). "Procedures developed for self-repair of polymer matrix composite materials." Composite Structures 35(3): 263-269.

Du, Y. J., M. Damron, et al. (2001). "Inorganic/organic hybrid coatings for aircraft aluminum alloy substrates." Progress in Organic Coatings 41(4): 226-232.

Engelberg, D. L. (2010). Shreir's Corrosion. R. J.A. Amsterdam, Elsevier.

Evans, U. R. (1971). "Inhibition, Passivity and Resistance. A Review of Acceptable Mechanisms." Electrochimica Acta 16(11): 1825-1840.

Fischer, H. R. (2010). natural Science 2: 873-901.

Fishkis, M. and J. C. Lin (1997). "Formation and evolution of a subsurface layer in a metalworking process." Wear 206(1-2): 156-170.

Forsyth, M., T. Markley, et al. (2008). "Inhibition of corrosion on AA2024-T3 by new environmentally friendly rare earth organophosphate compounds." Corrosion 64(3): 191-197.

Frankel, G. S. (1998). "Pitting corrosion of metals - A review of the critical factors." Journal of the Electrochemical Society 145(6): 2186-2198. 
Furman, S. A., F. H. Scholes, et al. (2006). "Corrosion in artificial defects. II. Chromate reactions." Corrosion Science 48(7): 1827-1847.

Gao, M., C. R. Feng, et al. (1998). "An analytical electron microscopy study of constituent particles in commercial 7075-T6 and 2024-T3 alloys." Metallurgical and Materials Transactions a-Physical Metallurgy and Materials Science 29(4): 1145-1151.

Garcia-Vergara, S., F. Colin, et al. (2004). "Effect of copper enrichment on the electrochemical potential of binary Al-Cu alloys." Journal of the Electrochemical Society 151(1): B16B21.

Garcia, S. J., H. R. Fischer, et al. (2011). "Self-healing anticorrosive organic coating based on an encapsulated water reactive silyl ester: Synthesis and proof of concept." Progress in Organic Coatings 70(2-3): 142-149.

García, S. J., Mol, J.M.C., Muster, T.H., Hughes, A.E., Mardel, J., Miller, T., Markely, T., Terryn, H., de Wit, J.H.W. (2011). Advances in the Selection and use of Rare-EarthBased Inhibitors for Self Healing Organic Coatings, Accepted for publication in Self-Healing Properties of New Surface Treatments. Green Inhibitors. L. Fedrizzi, EFC-Maney Publishing. 58.

Glenn, A. M., T. H. Muster, et al. (2011). "Corrosion of AA2024-T3 Part III: Propagation." Corrosion Science 53(1): 40-50.

Guillaumin, V. and G. Mankowski (1999). "Localized corrosion of 2024 T351 aluminium alloy in chloride media." Corrosion Science 41(3): 421-438.

Habazaki, H., K. Shimizu, et al. (1997). "Nanoscale enrichments of substrate elements in the growth of thin oxide films." Corrosion Science 39(4): 731-737.

Hahn, G. T. and A. R. Rosenfield (1975). "Metallurgical Factors Affecting Fracture Toughness of Aluminum-Alloys." Metallurgical Transactions A 6(4): 653-668.

Harlow, D. G., M. Z. Wang, et al. (2006). Metall. mat. Trans A 37A: 3367-3373.

Harvey, T. G., A. E. Hughes, et al. (2008). "Non-chromate deoxidation of AA2024-T3: Sodium bromate-nitric acid (20-60 degrees C)." Applied Surface Science 254(11): 3562-3575.

Hatch , J. E. (1984). Aluminium: Porperties and Physical Metallurgy, ASM International.

Hinton, B. R. W., N. Dubrule, et al. (2006). Raman, EDS and SEM studies of the interaction of corrosion inhibitor $\mathrm{Ce}(\mathrm{dbp})_{3}$ with AA2024-T3. 4th International Symposium on Aluminium Surface Science and Technology. Beaune, France.

Ho, D., N. Brack, et al. (2006). "Cerium dibutylphosphate as a corrosion inhibitor for AA2024-T3 aluminum alloys." Journal of the Electrochemical Society 153(9): B392B401.

Hughes, A. E., A. Boag, et al. (2011). "Corrosion of AA2024-T3 Part II Co-operative corrosion." Corrosion Science 53(1): 27-39.

Hughes, A. E., A. Boag, et al. (2006). Statistical Approach to Determine Spatial and Elemental Correlations of Corrosion Sites on Al-Alloys. Aluminium Surface Science and Technology Conference Beaune, France, ATB Metallurgie, 45 (1-4): 551-556.

Hughes, A. E., Cole, I.S., Muster, T.M. and Varley, R.J. (2010). "Combining Green and Self Healing for a new Generation of Coatings for Metal Protection." Nature Asia Materials 2(4): 143-151.

Hughes, A. E., B. Hinton, et al. (2007). "Airlife - Towards a fleet management tool for corrosion damage." Corrosion Reviews 25(3-4): 275-293.

Hughes, A. E., C. MacRae, et al. (2010). Surface Interface Analysis 42: 334-338. 
Hughes, A. E., J. M. C. Mol, et al. (2005). "A morphological study of filiform corrosive attack on cerated AA2024-T351 aluminium alloy." Corrosion Science 47(1): 107-124.

Hughes, A. E., T. H. Muster, et al. (2010). Corrosion Science Accepted.

Hughes, A. E., N. Wilson, et al. (2009). Corrosion Science 51: 1565-1568.

Hunter, M. S. F., G.R., Robinson, D.L. (1963). 2nd International Conference on Metallic Corrosion: 66.

Ilevbare, G. O., O. Schneider, et al. (2004). Journal of Electrochemical Society 151: B453-B464.

Ilevbare, G. O., O. Schneider, et al. (2004). "In situ confocal laser scanning microscopy of AA 2024-T3 corrosion metrology - I. Localized corrosion of particles." Journal of the Electrochemical Society 151(8): B453-B464.

Juffs, L. (2002). Investigation of Corrosion Coating Deposition on Microscopic and Macroscopic Intermetallic Phases of Aluminium Alloys. Melbourne, RMIT. Master of Science.

Juffs, L., A. E. Hughes, et al. (2002). "The use of macroscopic modelling of intermetallic phases in aluminium alloys in the study of ferricyanide accelerated chromate conversion coatings." Corrosion Science 44(8): 1755-1781.

Juffs, L., A. E. Hughes, et al. (2001). "The use of macroscopic modelling of intermetallic phases in aluminium alloys in the study of ferricyanide accelerated chromate conversion coatings." Micron 32(8): 777-787.

Jung, D. Y., I. Dumler, et al. (1985). "Electronmicroscopic Examination of Corroded Aluminum-Copper Alloy Foils." Journal of the Electrochemical Society 132(10): 2308-2312.

Kendig, M. W. and R. G. Buchheit (2003). "Corrosion inhibition of aluminum and aluminum alloys by soluble chromates, chromate coatings, and chromate-free coatings." Corrosion 59(5): 379-400.

Khramov, A. N., N. N. Voevodin, et al. (2004). "Hybrid organo-ceramic corrosion protection coatings with encapsulated organic corrosion inhibitors." Thin Solid Films 447: 549557.

Knight, S. P. (2003). "A review of HEat Treatments." Australasian Corrosion Association.

Kolics, A., A. S. Besing, et al. (2001). "Interaction of chromate ions with surface intermetallics on aluminum alloy 2024-T3 in $\mathrm{NaCl}$ solutions." Journal of the Electrochemical Society 148(8): B322-B331.

Kovarik, L., M. K. Miller, et al. (2006). "Origin of the modified orientation relationship for S(S")-phase in Al-Mg-Cu alloys." Acta Materialia 54(7): 1731-1740.

Lacroix, L., L. Ressier, et al. (2008). "Combination of AFM, SKPFM, and SIMS to study the corrosion behavior of S-phase particles in AA2024-T351." Journal of the Electrochemical Society 155(4): C131-C137.

Lacroix, L., L. Ressier, et al. (2008). "Statistical study of the corrosion behavior of Al2CuMg intermetallics in AA2024-T351 by SKPFM." Journal of the Electrochemical Society 155(1): C8-C15.

Leth-Olsen, H., J. H. Nordlien, et al. (1997). "Formation of Nanocrystalline Surface Layers by Annealing and Their Role in Filiform Corrosion of Aluminum Sheet." Journal of the Electrochemical Society 144(7): L196-L197.

Leth-Olsen, H., J. H. Nordlien, et al. (1998). "Filiform corrosion of aluminium sheet. III. Microstructure of reactive surfaces." Corrosion Science 40(12): 2051-2063. 
Liao, C. M., J. M. Olive, et al. (1998). "In-situ monitoring of pitting corrosion in aluminum alloy 2024." Corrosion 54(6): 451-458.

Liu, Y., M. F. Frolish, et al. (2010). "Evolution of near-surface deformed layers during hot rolling of AA3104 aluminium alloy." Surface And Interface Analysis 42(4): 180-184.

Liu, Y., A. Laurino, et al. (2010). "Corrosion behaviour of mechanically polished AA7075-T6 aluminium alloy." Surface And Interface Analysis 42(4): 185-188.

Liu, Y., X. Zhou, et al. (2007). "Precipitation in an AA6111 aluminium alloy and cosmetic corrosion." Acta Materialia 55(1): 353-360.

Luo, C., Hughes, A.E., Zhou X., Thompson G.E. (to be published). Corrosion Science.

Mahajanarn, S. P. V. and R. G. Buchheit (2008). "Characterization of inhibitor release from Zn-Al- V10O28 (6-) hydrotalcite pigments and corrosion protection from hydrotalcite-pigmented epoxy coatings." Corrosion 64(3): 230-240.

Mao, Y., A. M. Gokhale, et al. (2006). Computational Materials Science 37: 543-556.

Mardel, J., S. J. Garcia, et al. (2011). "The characterisation and performance of Ce(dbp)3inhibited epoxy coatings." Progress in Organic Coatings 70(2-3): 91-101.

Markley, T. A., M. Forsyth, et al. (2007). "Corrosion protection of AA2024-T3 using rare earth diphenyl phosphates." Electrochimica Acta 52(12): 4024-4031.

Markley, T. A., A. E. Hughes, et al. (2007). "Influence of praseodymium - Synergistic corrosion inhibition in mixed rare-earth diphenyl phosphate systems." Electrochemical and Solid State Letters 10(12): C72-C75.

Mazurkiewicz, B. and A. Piotrowski (1983). "The Electrochemical-Behavior of the Al2cu Intermetallic Compound." Corrosion Science 23(7): 697-\&.

Meng, Q. J. and G. S. Frankel (2004). The effect of Cu content on the localized corrosion resistance of AA7xxx-T6 alloys. Corrosion and Protection of Light Metal Alloys. R. G. Buchheit, R. G. Kelly, N. A. Missert and B. A. Shaw. 2003: 62-81.

Mol, J. M. C., A. E. Hughes, et al. (2004). "A morphological study of filiform corrosive attack on chromated and alkaline-cleaned AA2024-T351 aluminium alloy." Corrosion Science 46(5): 1201-1224.

Mookhoek, S. D., H. R. Fischer, et al. (2009). "A numerical study into the effects of elongated capsules on the healing efficiency of liquid-based systems." Computational Materials Science 47(2): 506-511.

Mookhoek, S. D., S. C. Mayo, et al. (2010). "Applying SEM-Based X-ray Microtomography to Observe Self-Healing in Solvent Encapsulated Thermoplastic Materials." Advanced Engineering Materials 12(3): 228-234.

Muster, T. H., Hughes, A.E., Thompson. G.E. (2009). Cu Distributions in Aluminium Alloys. New York, Nova Science Publishers.

Newman, R. C. and K. Sieradzki (1994). "Metallic Corrosion." Science 263(5154): 1708-1709.

Nisancioglu, K. S., O., Yu, Y., Nordlien, Y.K. (2004). 55th Annula Meeting of the International Society of Electrochemistry, Thessaloniki.

Osborne, J. H., K. Y. Blohowiak, et al. (2001). "Testing and evaluation of nonchromated coating systems for aerospace applications." Progress in Organic Coatings 41(4): 217-225.

Pan, X., J. E. Morral, et al. (2010). "Predicting the Q-Phase in Al-Cu-Mg-Si Alloys." Journal of Phase Equilibria and Diffusion 31(2): 144-148.

Park, J. O., C.-H. Paik, et al., Eds. (1996). Critical Factors in Localised Corrosion II., The Electrochemical Society, Pennington, NJ. 
Park, J. O., C.-H. Paik, et al. (1999). Journal of the Electrochemical Society 146: 517-523.

Phragmen, G. (1950). "On the Phases Occurring in Alloys of Aluminium with Copper, Magnesium, Manganese, Iron and Silicon." The Journal of the Institute of Metals 77: 489-553.

Plassart, G., Aucouturier, M. (2000). 2nd International Conference on Aluminium Surface Science and Technology. Manchester: 29 - 35.

Poelman, M., M. G. Olivier, et al. (2005). "Electrochemical study of different ageing tests for the evaluation of a cataphoretic epoxy primer on aluminium." Progress in Organic Coatings 54(1): 55-62.

Polmear, I. J. (1995). Light Allopys: Metallurgy of the Light Metals. London, Arnold.

Polmear, I. J. (2004). "A Century of Age Hardening." Materials Forum 28: 1 - 14.

Pride, S. T., J. R. Scully, et al. (1994). "Metastable Pitting of Aluminum and Criteria for the Transition to Stable Pit Growth." Journal of the Electrochemical Society 141(11): 3028-3040.

Pryor, M. J. and J. C. Fister (1984). "The Mechanism of Dealloying of Copper Solid-Solutions and Intermetallic Phases." Journal of the Electrochemical Society 131(6): 1230-1235.

Ralston, K. D., N. Birbilis, et al. (2010). "The effect of precipitate size on the yield strengthpitting corrosion correlation in Al-Cu-Mg alloys." Acta Materialia 58(18): 5941-5948.

Raps, D., T. Hack, et al. (2009). "Electrochemical study of inhibitor-containing organicinorganic hybrid coatings on AA2024." Corrosion Science 51(5): 1012-1021.

Raviprasad, K., C. R. Hutchinson, et al. (2003). "Precipitation processes in an Al-2.5Cu-1.5Mg (wt. \%) alloy microalloyed with Ag and Si." Acta Materialia 51(17): 5037-5050.

Samadzadeh, M., S. H. Boura, et al. (2010). "A review on self-healing coatings based on micro/nanocapsules." Progress in Organic Coatings 68(3): 159-164.

Sasaki, K., P. W. Levy, et al. (2002). "Electrochemical noise during pitting corrosion of aluminum in chloride environments." Electrochemical and Solid State Letters 5(8): B25-B27.

Scamans, G. M., Afseth, A., Thompson, G.E., Zhou X (2000). 2 nd International Conference on Aluminium Surface Science and Technology. Manchester: 9 - 15.

Scamans, G. M., M. F. Frolish, et al. (2010). "The ubiquitous Beilby layer on aluminium surfaces." Surface And Interface Analysis 42(4): 175-179.

Schneider, O., G. O. Ilevbare, et al. (2004). Journal of Electrochemical Society 151(B\$65-B472).

Schneider, O., G. O. Ilevbare, et al. (2004). "In situ confocal laser scanning microscopy of AA 2024-T3 corrosion metrology - II. Trench formation around particles." Journal of the Electrochemical Society 151(8): B465-B472.

Scholes, F. H., S. A. Furman, et al. (2006). "Chromate leaching from inhibited primers - Part I. Characterisation of leaching." Progress in Organic Coatings 56(1): 23-32.

Scholes, F. H., A. E. Hughes, et al. (2009). "Interaction of Ce(dbp)(3) with surface of aluminium alloy 2024-T3 using macroscopic models of intermetallic phases." Corrosion Engineering Science and Technology 44(6): 416-424.

Scully, J. R., T. O. Knight, et al. (1993). "Electrochemical Characteristics of the Al2cu, Al3ta And Al3zr Intermetallic Phases and Their Relevancy to the Localized Corrosion of Al-Alloys." Corrosion Science 35(1-4): 185-195.

Searles, J. L., P. I. Gouma, et al. (2001). "Stress corrosion cracking of sensitized AA5083 (Al4.5Mg-1.0Mn)." Metallurgical and Materials Transactions a-Physical Metallurgy and Materials Science 32(11): 2859-2867. 
Seri, O. (1994). "The Effect of Nacl Concentration on the Corrosion Behavior of AluminumContaining Iron." Corrosion Science 36(10): 1789-\&.

Sieradzki, K. (1993). "Curvature Effects in Alloy Dissolution." Journal of the Electrochemical Society 140(10): 2868-2872.

Sinko, J. (2001). "Challenges of chromate inhibitor pigments replacement in organic coatings." Progress in Organic Coatings 42(3-4): 267-282.

Souto, R. M., Y. González-García, et al. (2010). "Examination of organic coatings on metallic substrates by scanning electrochemical microscopy in feedback mode: Revealing the early stages of coating breakdown in corrosive environments." Corrosion Science 52(3): 748-753.

Sprowls, D. O. (1978). "High Strength Aluminium Alloys with Improved Resistance to Corrosion and Stress Corrosion Cracking." Aluminium 54(6): 214 - 217.

Suryanarayana, C., K. C. Rao, et al. (2008). "Preparation and characterization of microcapsules containing linseed oil and its use in self-healing coatings." Progress in Organic Coatings 63(1): 72-78.

Suter, T., Alkire, R.C. (2001). "Microelectrochemical Studies of Pit Initiation at Single Inclusions in Al 2024-T3." jJournal of the Electrochemical Society 148(1): B36-B42.

Taylor, S. R. and B. D. Chambers (2008). "Identification and characterization of nonchromate corrosion inhibitor synergies using high-throughput methods." Corrosion 64(3): 255-270.

Tedim, J., S. K. Poznyak, et al. (2010). "Enhancement of Active Corrosion Protection via Combination of Inhibitor-Loaded Nanocontainers." Acs Applied Materials \& Interfaces 2(5): 1528-1535.

Thompson, G. E. a. Z. X. (2010). Mater. World 18: 26-27.

Trueman, A. R. (2005). "Determining the probability of stable pit initiation on aluminium alloys using potentiostatic electrochemical measurements." Corrosion Science 47(9): 2240-2256.

Twite, R. L. and G. P. Bierwagen (1998). "Review of Alternatives to Chromate for Corrosion Protection of Aluminum Aerospace Alloys." Progress in Organic Coatings 33(2): 91100.

Voevodin, N. N., V. N. Balbyshev, et al. (2003). "Nanostructured coatings approach for corrosion protection." Progress in Organic Coatings 47(3-4): 416-423.

Vukmirovic, M. B., N. Dimitrov, et al. (2002). "Dealloying and corrosion of Al alloy 2024-T3." Journal of the Electrochemical Society 149(9): B428-B439.

Wadeson, D. A., X. Zhou, et al. (2006). "Corrosion behaviour of friction stir welded AA7108 T79 aluminium alloy." Corrosion Science 48(4): 887-897.

Wei, R. P., C. M. Liao, et al. (1998). "A transmission electron microscopy study of constituent-particle-induced corrosion in 7075-T6 and 2024-T3 aluminum alloys." Metallurgical and Materials Transactions a-Physical Metallurgy and Materials Science 29(4): 1153-1160.

White, P. A., A. E. Hughes, et al. (2009). "High-throughput channel arrays for inhibitor testing: Proof of concept for AA2024-T3." Corrosion Science 51(10): 2279-2290.

White, S. R., N. R. Sottos, et al. (2001). "Autonomic healing of polymer composites." Nature 409(6822): 794-797. 
Williams, G. and H. N. McMurray (2003). "Anion-exchange inhibition of filiform corrosion on organic coated AA2024-T3 aluminum alloy by hydrotalcite-like pigments." Electrochemical and Solid State Letters 6(3): B9-B11.

Winkelman, G. B., K. Raviprasad, et al. (2007). "Orientation relationships and lattice matching for the S phase in Al-Cu-Mg alloys." Acta Materialia 55(9): 3213-3228.

Wloka, J. and S. Virtanen (2008). "Detection of nanoscale eta-MgZn2 phase dissolution from an Al-Zn-Mg-Cu alloy by electrochemical microtransients." Surface and Interface Analysis 40(8): 1219-1225.

Wu, D. Y., S. Meure, et al. (2008). "Self-healing polymeric materials: A review of recent developments." Progress in Polymer Science 33(5): 479-522.

Yin, T., M. Z. Rong, et al. (2007). "Self-healing epoxy composites - Preparation and effect of the healant consisting of microencapsulated epoxy and latent curing agent." Composites Science and Technology 67(2): 201-212.

Zamin, M. (1981). "The Role of Mn in the Corrosion Behavior of Al-Mn Alloys." Corrosion 37(11): 627-632.

Zhang, W. L. and G. S. Frankel (2003). "Transitions between pitting and intergranular corrosion in AA2024." Electrochimica Acta 48(9): 1193-1210.

Zhao, X. Y. and G. S. Frankel (2007). "Quantitative study of exfoliation corrosion: Exfoliation of slices in humidity technique." Corrosion Science 49(2): 920-938.

Zheludkevich, M. L., I. M. Salvado, et al. (2005). "Sol-gel coatings for corrosion protection of metals." Journal of Materials Chemistry 15(48): 5099-5111.

Zhou, X., G. E. Thompson, et al. (2003). "The influence of surface treatment on filiform corrosion resistance of painted aluminium alloy sheet." Corrosion Science 45(8): 1767-1777.

Zhou, X. L., Y., Thompson, G.E., Scamans, G.M., Skeldon, P., Hunter, J.A. (2011). "NearSurface Deformed Layers on Rolled Aluminium Alloys." Metallurgical and Materials Transactions A: Physical Metallurgy and Materials Science.

Zin, I. M., R. L. Howard, et al. (1998). "The mode of action of chromate inhibitor in epoxy primer on galvanized steel." Progress in Organic Coatings 33(3-4): 203-210. 


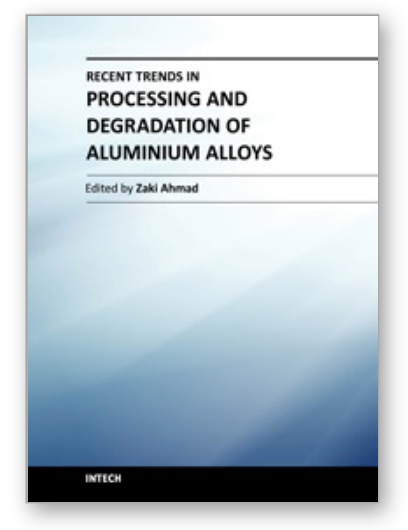

\section{Recent Trends in Processing and Degradation of Aluminium Alloys \\ Edited by Prof. Zaki Ahmad}

ISBN 978-953-307-734-5

Hard cover, 516 pages

Publisher InTech

Published online 21, November, 2011

Published in print edition November, 2011

In the recent decade a quantum leap has been made in production of aluminum alloys and new techniques of casting, forming, welding and surface modification have been evolved to improve the structural integrity of aluminum alloys. This book covers the essential need for the industrial and academic communities for update information. It would also be useful for entrepreneurs technocrats and all those interested in the production and the application of aluminum alloys and strategic structures. It would also help the instructors at senior and graduate level to support their text.

\section{How to reference}

In order to correctly reference this scholarly work, feel free to copy and paste the following:

Anthony E. Hughes, Nick Birbilis, Johannes M.C. Mol, Santiago J. Garcia, Xiaorong Zhou and George E. Thompson (2011). High Strength Al-Alloys: Microstructure, Corrosion and Principles of Protection, Recent Trends in Processing and Degradation of Aluminium Alloys, Prof. Zaki Ahmad (Ed.), ISBN: 978-953-307-734-5, InTech, Available from: http://www.intechopen.com/books/recent-trends-in-processing-and-degradation-ofaluminium-alloys/high-strength-al-alloys-microstructure-corrosion-and-principles-of-protection

\section{INTECH}

open science | open minds

\section{InTech Europe}

University Campus STeP Ri Slavka Krautzeka 83/A 51000 Rijeka, Croatia Phone: +385 (51) 770447 Fax: +385 (51) 686166 www.intechopen.com

\section{InTech China}

Unit 405, Office Block, Hotel Equatorial Shanghai No.65, Yan An Road (West), Shanghai, 200040, China 中国上海市延安西路65号上海国际贵都大饭店办公楼 405 单元 Phone: +86-21-62489820

Fax: $+86-21-62489821$ 
(C) 2011 The Author(s). Licensee IntechOpen. This is an open access article distributed under the terms of the Creative Commons Attribution 3.0 License, which permits unrestricted use, distribution, and reproduction in any medium, provided the original work is properly cited. 